\title{
Internationalists and locals: international research collaboration in a resource-poor system
}

\author{
Marek Kwiek $^{1}$ (D)
}

Received: 10 January 2019 / Published online: 28 April 2020

(c) The Author(s) 2020

\begin{abstract}
The principal distinction drawn in this study is between research "internationalists" and "locals." The former are scientists involved in international research collaboration while the latter group are not. These two distinct types of scientist compete for academic prestige, research funding, and international recognition. International research collaboration proves to be a powerful stratifying force. As a clearly defined subgroup, internationalists are a different academic species, accounting for $51.4 \%$ of Polish scientists; predominantly male and older, they have longer academic experience and higher academic degrees and occupy higher academic positions. Across all academic clusters, internationalists consistently produce more than $90 \%$ of internationally co-authored publications, representing $2320 \%$ of locals' productivity for peer-reviewed articles and $1600 \%$ for peer-reviewed article equivalents. Internationalists tend to spend less time than locals on teaching-related activities, more time on research, and more time on administrative duties. Based on a large-scale academic survey $(N=3704)$, some new predictors of international research collaboration were identified by multivariate analyses. The findings have global policy implications for resource-poor science systems "playing catch-up" in terms of academic careers, productivity patterns, and research internationalization policies.
\end{abstract}

Keywords Research collaboration - Academic career · Productivity patterns · Internationalization $\cdot$ Aging and collaboration $\cdot$ Gender disparity $\cdot$ Poland

\section{Introduction}

The principal distinction drawn here is between research "internationalists" and "locals." The former are scientists involved in international research collaboration while the latter group are not. These two distinct types compete for academic prestige and professional recognition (Wagner and Leydesdorff 2005), research funding (Jeong et al. 2014), and international scientific recognition (Merton 1973). While locals produce knowledge for "national research markets" and audiences (Ziman 1991), internationalists produce knowledge for international (or local and international) markets and

Marek Kwiek

kwiekm@amu.edu.pl

1 University of Poznan, Poznan, Poland 
audiences. As reward systems operate differently across countries and academic disciplines, seeking international recognition rather than national recognition is reported to be more or less "necessary" (Kyvik and Larsen 1997: 260), depending on country affiliation and discipline.

Academic discipline, employing institution and type, and national reward structure all influence international research collaboration. However, the decision to internationalize is ultimately personal, and concepts such as "self-organization" (Wagner and Leydesdorff 2005: 1610; Melin 2000: 39; Wagner 2018: 84) and "informal collaboration" beyond formal agreements (Georghiou 1998: 612) are especially relevant in this regard. Within the global knowledge network, the motivation to internationalize comes from scientists themselves, and "political ties or national prestige do not motivate the alliances of researchers" (Wagner 2018: viii). Faculty internationalization is reported to be disproportionately shaped by deeply ingrained individual values and predilections (Finkelstein, Walker, and Chen 2013), and scientists vary in their tendency to collaborate internationally: "The more elite the scientist, the more likely it is that he or she will be an active member of the global invisible college" (Wagner 2008: 15) — that is, the more likely they are to collaborate with colleagues in other countries (Kwiek 2016).

Previous studies have shown that the share of internationalists among Polish academics is substantially lower than the Western European average, and their role in Polish academic knowledge production is substantially higher (Kwiek 2015a). In Europe, Poland is among those countries with the lowest share of internationalists. In a recent study of 11 countries, the mean share of internationalists among European scientists employed full-time in the university sector was $63.8 \%$ (Kwiek 2018b); in Poland, internationalists account for just $51.4 \%$. As measured by a proxy of internationally co-authored publications, Poland had the lowest level of research internationalization in the European Union in 2018 (35.8\% based on Scopus data). There are many underlying reasons, but in general terms, this relates to the systematic "deinstitutionalization" of Polish universities' research mission since about 2010 , followed by a slow "reinstitutionalization" powered by two waves of higher education reforms in the last decade (for overviews of the Polish higher education and science systems, see Antonowicz 2016; Antonowicz et al. 2017; Dakowska 2015; Urbanek 2018; Bieliński and Tomczyńska 2018; Ostrowicka and Stankiewicz 2018; Wolszczak-Derlacz and Parteka 2010). To increase the international visibility of Polish science, current reforms (under "Law 2.0") include new funding formulas, a revised research assessment exercise (expected in 2021), and the selection in 2019 of ten "research universities" for additional funding in 2020-2026 within a new "national excellence initiative." In practice, as in all science systems "playing catch-up," the direction of change is clear: to increase publication in international journals and the number of internationally co-authored publications.

Certain scientists are clearly more internationalized than others, and this distinction permeates Polish research. As more international collaboration tends to mean higher publishing rates (and higher citation rates), internationalization plays an increasingly stratifying role within the academic profession., Increasingly, those who do not collaborate internationally are likely to suffer internationalization accumulative disadvantage in terms of resources and prestige. (The term "accumulative disadvantage" was originally used by Cole and Cole 1973: 146). Research internationalization divides the academic community, both across institutions (vertical differentiation) and across faculties within institutions (horizontal segmentation), and highly internationalized institutions, faculties, research groups and individual scientists and less internationalized counterparts emerge. For internationalists, the key reference group is the international academic community; in contrast, locals focus predominantly on the national academic community. 
The present study addresses the following research questions. What distinguishes research internationalists from research locals? Are internationalists distinctive in terms of who they are, how they work, or what they think about their academic work? In short, are internationalists a different species within the resource-poor Polish higher education system?

Based on a large-scale academic survey ( $N=3704$ returned questionnaires), this study has global implications for academic career and productivity patterns and contributes to a better understanding of "the collaborative era in science" (Wagner 2018) by contrasting the prototypical figure of the internationalist with the local research scientist.

The paper is structured as follows. The next section describes the theoretical framework, followed by data and methods. The results section includes an overview of internationalists, patterns of individual research productivity and international collaboration, patterns of individual research productivity by publication type, a bivariate analysis of working time distribution and teaching and research role, and a multivariate analysis. The logistic regression analysis is in two parts; model approach (I) examines predictors of collaboration with international colleagues in research, and model approach (II) looks at how various aspects of internationalization influence research productivity. The paper ends with a summary of the findings, followed by discussion and conclusions.

\section{Theoretical framework}

\section{Studying international research collaboration}

Before moving to more specialized literature, let us briefly describe what is often assumed in international collaboration studies. First, impediments to international research collaboration may include macro-level factors (geopolitics, history, language, cultural traditions, country size, country wealth, geographical distance); organizational factors (reputation, resources); and individual factors (predilections, attractiveness as a researcher in terms of possible input and expertise etc.) (Hoekman et al. 2010; Luukkonen et al. 1992).

Second, international research collaboration is reported to have costs as well as benefits (Katz and Martin 1997; Jeong et al. 2014). According to Katz and Martin, "With more people and perhaps several institutions involved, greater effort is required to manage the research" (1997: 16). Specifically, transaction costs (Georghiou 1998) and coordination costs (Cummings and Kiesler 2007) are higher for international research collaboration. In collaborative research, there is a trade-off between increased publication and research funds and the need to minimize transaction costs (Landry and Amara 1998). Collaboration involving multiple universities also complicates coordination and may undermine project outcomes (Cummings and Kiesler 2007). Furthermore, while research collaboration with highly productive scientists generally increases individual productivity, collaboration with low-productivity scientists is reported to have the opposite effect (Lee and Bozeman 2005).

Third, international research collaboration can be viewed as an emergent, self-organizing, networked system, in which the selection of partners and research settings often relies on the researchers themselves. In more spontaneous or bottom-up collaborations, what matters is "the individual interests of researchers seeking resources and reputation" (Wagner and Leydesdorff 2005: 1616). Most research collaborations begin with face-to-face meetings, especially at conferences (Melin 2000). Scientists connect with each other "on a peer-to-peer level, and a process of preferential attachment selects specific individuals into 
an increasingly elite circle. The process reduces free riders and greatly increases the visibility of parts of the system" (Wagner 2018: x).

Fourth, according to resource allocation theory, the attentional resources that scientists and their teams can invest in research (commitment and time) are always limited. This theory holds that "the resources allocated to a function will decrease as resources allocated to other functions increase" (Jeong, Choi, and Kim 2014: 523). Consequently, the decision to engage in research teamwork "is ultimately a resource allocation decision by which members must decide how to best allocate their limited resources" (Porter et al. 2010: 241), as time is often a more valuable resource than research funding (Katz and Martin 1997). Additional demands can reduce the available time and energy for actual research activities (Jeong et al. 2011). Collaboration also involves personal decisions based on "trust" and "confidence" (Knorr Cetina 1999), as well as "purpose", involving multiple issues that range from "access to expertise" to "enhancing productivity" (Beaver 2001: 373).

Fifth, collaboration is largely a matter of social convention among scientists and therefore difficult to define; what constitutes a collaboration varies across levels (individuals, institutions) and changes over time (Katz and Martin 1997). Beyond the "sole research" mode, it is important to distinguish clearly between "internal" collaboration (within the same organization), "domestic" collaboration (within the same country), and "international" collaboration (between countries) (Jeong et al. 2011: 969). In general, research collaboration can be defined as a "system of research activities by several actors related in a functional way and coordinated to attain a research goal corresponding with these actors' research goals or interests" (Laudel 2002: 5). In other words, collaboration presupposes a shared research goal, is defined by activities rather than by the actors involved, and refers only to research that includes personal interactions. By this definition, collaboration need not have any publication objective at any point (Sooryamoorthy 2014). However, as broader notions of collaboration are not easy to measure, many studies of research collaboration "begin and end with the co-authored publication" (Bozeman and Boardman 2014: 2-3).

Finally, international research collaboration can be said to have two prerequisites: the researcher's motivation and their attractiveness (as a researcher) to international colleagues (Kyvik and Larsen 1994; Wagner 2008). The potential to join international research networks depends on one's attractiveness as a research partner (Wagner and Leydesdorff 2005). In this regard, "Visibility is a basic condition for being potentially interesting to other scientists, but one also has to be attractive in order to be actively sought out by others" (Kyvik and Larsen 1994: 163). Also availability of resources increases the level of international research collaboration (Kyvik and Larsen 1997; Jeong et al. 2014). Beyond that, scientists create and sustain the connections that form the global knowledge network largely because they "become resources to others ... connections are retained as long as they are of mutual (or potential) interest to participating members" (Wagner 2018: 62). In short, networks mean (international) collaboration.

\section{International research collaboration and reward structures in science}

Gouldner (1957) distinguished between scientists who are less research-oriented and more loyal to their employing organization (locals) and those who are less loyal to their organization and more research-oriented (cosmopolitans). These pure types have subsequently been reformulated in both organizational studies and higher education research (Rhoades et al. 2008; Smeby and Gornitzka 2008). According to Robert K. Merton's sociology of 
science (1973: 374), outstanding scientists are more likely to be "cosmopolitans" who are oriented to wider "national and trans-national environments" while "locals" tend to be oriented "primarily to their immediate band of associates" or local peers.

Centering on the concept of "mobility," the distinction originally referred to organizational roles and to professional identities and norms rather than research internationalization. Gouldner argued that professionals identify with a reference group and refer to it in making judgments about their own performance. Distinguishing immobile and institutionoriented scientists (loyal to inside reference groups) from mobile, cosmopolitan, careeroriented scientists (loyal to outside reference groups), cosmopolitans and locals can be said to differ sharply in their attitude to research, sources of recognition, and academic career trajectories (Wagner and Leydesdorff 2005). In their study of Norwegian scientists, Kyvik and Larsen related the local/cosmopolitan opposition to publishing modes rather than to international collaboration: "while locals can be said to have the Norwegian scholarly community as a frame of reference, cosmopolitans take the values and standards of the international scientific community as a comparative frame of reference" (1997: 261).

As incentive and reward systems in European science evolve to become more outputoriented (Kyvik and Aksnes 2015; Kwiek 2019), individual scientists are under increasing pressure to become internationalists by cooperating and co-publishing internationally. Performance-based funding and awareness of international research-based university rankings mean that scholarly publishing is closely linked to institutional and/or departmental funding, and collaboration is increasing at author, institution, and country levels (Gazni et al. 2012). The Mertonian principle of priority of discovery suggests that international research collaboration is driven primarily by reward structures in highly competitive science systems, especially in the hard sciences (Kyvik and Larsen 1997). As Wagner and Leydesdorff have argued, "the many individual choices of scientists to collaborate may be motivated by reward structures within science where co-authorships, citations and other forms of professional recognition lead to additional work and reputation in a virtuous circle" (Wagner and Leydesdorff 2005: 1616).

Massive international research collaboration can be understood as an emergent, selforganizing, networked system, in which partners and research settings are often selected by the researchers themselves (Wagner 2018). With changing reward structures and the new opportunities afforded by information and communication technologies, individual scientists increasingly cooperate internationally in what can be described as a process of "preferential attachment," as certain individuals are admitted to an increasingly elite circle (Wagner 2018: x). The omnipresence of internationalists changes how science is perceived, and non-collaboration is increasingly rare, even in the traditionally sole-authored humanities. In that context, Poland is an interesting outlier, with the lowest share of internationally co-authored publications in Europe (Kwiek 2020; Scopus 2020) and one of the lowest shares of scientists reporting international collaboration in Europe.

\section{Survey-based and bibliometric studies}

While the two contrasted prototypical figures of internationalists and locals in research were not used in previous research, the vast literature on international collaboration in research was instrumental in developing the hypotheses, using bibliometric and survey-based studies 
of international collaboration in research. For example, Kwiek (2015a) looked at internationalists and locals in 11 European systems. Rostan et al. (2014) and Finkelstein and Sethi (2014) analyzed internationally collaborating and non-collaborating scholars in 19 countries, and Cummings and Finkelstein (2012) contrasted a minority of "internationalists" with their "insular peers" in the USA. All four studies were based on survey data juxtaposing collaborating and non-collaborating scientists. Two large-scale international comparative studies of the changing academic profession (CAP and EUROAC; see subsection on the dataset below), published successively in the last 10 years provide useful data. In contrast to the present case, most bibliometric studies refer to international research collaboration defined as production of internationally co-authored publications rather than as research conducted with international collaborators. Nevertheless, both survey and bibliometric approaches contributed to the development of our hypotheses, as they are closely linked and examine related phenomena.

\section{International research collaboration and gender}

Beyond the numerous studies on general research collaboration and gender, several surveybased studies have focused specifically on the role of gender in international research collaboration. In most cases, the findings indicate that being female is a negative predictor of international research collaboration (Rostan et al. 2014; Vabø et al. 2014; Kwiek 2018a). To cite one survey-based global study, "the prototypical academic figure in international research collaboration is a man, in his mid 50s or younger, working as a professor in a field of the natural sciences at a university" (Rostan et al. 2014: 130).

In their study of gender and international collaboration, Vabø et al. (2014: 191) found that female scientists report lower international research collaboration than males, regardless of the intensity of international collaboration within the regions studied. While male scientists are generally more involved in international research collaboration, female academics tend to be more involved in internationalization at home-for instance, teaching in a foreign language (Vabø et al. 2014: 202).

Being male significantly increases the odds of involvement in international research collaboration (by 69\%) in 11 European countries (see Kwiek 2018a). In Fox et al. (2017: 1304), women engineers identified funding and finding collaborators as external barriers to internationalization while personal or family concerns were perceived as significantly less important barriers for themselves than for others. Although in the 2000s, the success rate of research grant applications for female scientists in Poland has been lower than for male scientists, recent data indicate that the trend is reversing, especially for younger generations (Siemieńska 2019). For an account of how science globalization perpetuates gender inequalities and disadvantages women scientists, see Zippel (2017). For an account of internationalization (and especially international mobility) as "indirect discrimination" against women scientists, see Ackers (2008).

Bibliometric research on gender disparity in international collaboration has been conducted in Norway and Italy. The general conclusion was that the propensity to collaborate internationally in research was similar for both male and female scientists (Norway) or higher for male scientists across the whole population but similar for male and female top performers (Italy). Successive studies have addressed the gap in research on gender differences in research collaboration in general, and international research collaboration in particular, by taking the individual scientist as the base unit of analysis for both whole populations and top performers at national level. In the case of all Italian scientists, Abramo 
et al. (2013) showed that women scientists are more likely to collaborate domestically both intramurally and extramurally but are less likely to engage in extramural international collaboration. The study methodology avoids distortion by outliers-that is, by cases of highly productive and highly internationalized scientists whose extensive publications distort aggregate index values (Abramo et al. 2013: 820; similar gender disparities in international research collaboration were shown in a study of 25,000 university professors in Poland in Kwiek and Roszka 2020).

In Norway, Aksnes et al. (2019) used the Cristin bibliographic database (Norwegian Science Index of all peer-reviewed publications) to study gender differences in international collaboration across the four largest universities. Again, the unit of analysis was the individual scientist; counting all individuals equally as single units, regardless of productivity (Aksnes et al. 2019: 8), limited the effect of the outliers present in all systems. Analyzed by field, academic position and publication productivity, scientific discipline emerged as the most important determinant of international research collaboration while gender differences were not statistically significant. Bibliometric gender-focused analyses indicate no significant gender differences in overall propensity to collaborate among top scientists, which is similar for female and males (Abramo et al. 2019: 11).

\section{International research collaboration by age, academic generation, and rank}

There are few studies of age, academic rank, and international research collaboration because few datasets combine biographical and publication or citation data at the individual level. These combinations can be studied at the level of individual institutions, but large-scale studies at national level depend on dataset mergers (in Italy, see Abramo et al. 2011a; 2016; in Poland, our ongoing work is based on a merged dataset of 100,000 scientists and 400,000 articles from 2009 to 2018) or comprehensive national databases such as Norway's Cristin. Given the policy challenge posed by the progressive aging of European academic faculty, data-driven studies of national populations of scientists are especially useful. For example, in a major study of all Italian full professors, Abramo et al. (2016: 318) concluded that productivity declines significantly with age. However, professors appointed at a young age were more likely to maintain and increase their productivity than colleagues promoted at a later age. The age/productivity nexus has been widely studied in recent decades (see for example, Stephan and Levin 1992), leading to an investment-motivated model of scientific productivity in which scientists become less productive as they age (see Kyvik 1990; Kyvik and Olsen 2008). However, the age-related productivity of all scientists has only recently been compared to the productivity of top performers. In their bibliometric study of Spanish National Research Council scientists, based on a class-based approach (top, medium, and low performance), Costas et al. (2010) concluded that the productivity of top- and medium-performing scientists increases or remains stable with age, decreasing for them only among older scientists. In contrast, the productivity of lowperforming researchers tends to decrease with age (Costas et al. 2010: 1578). In a study of age and productivity of Italian National Research Council scientists, Bonaccorsi and Daraio (2003: 75) concluded that productivity declines with age and that the average age of researchers is increasing, with severe policy implications for national science systems.

Theoretically, international research collaboration can be studied by age, academic cohort (or academic generation), and period, so that age effects, cohort effects, and period effects need to be carefully distinguished. However, in practical terms, "except under conditions that hardly ever exist, a definitive separation of age, period, and cohort effects is not just difficult, but impossible" (Glenn 2005: vii). As this research is cross-sectional 
(only longitudinal data follow scientists over time), age and cohort (generational) effects are intermingled. Differences shown by age may or may not be age effects because Polish scientists of different ages studied through the survey instrument are members of different cohorts and "may have been shaped by different formative experiences and influences", with differences between them possibly being cohort effects (Glenn 2005: 3). All we learn from our research is about male and female scientists of varying ages in the period when our survey was conducted (and the various methods for estimating age, period, and cohort effects are not used in regression analysis in Sect. 4). Although clearly "cohort matters" (Stephan 2012: 175), cohort analysis par excellence cannot be conducted based on the dataset at our disposal. Belonging to a specific historical generation can have an influence on individual productivity (Kwiek 2019), and individual opportunities to engage in international collaboration differ by period (Rostan et al. 2014: 125). Here, "generation" may refer to "biographical generation" (expressed as biological age) or "status generation" (expressed as career stage) (Jung et al. 2014). Seniority by age and by career stage tend to overlap in most countries, including Poland, as indicated by an integrated biographical and publication database (created and maintained by the author) of all 100,000 Polish academic scientists. Survey-based cross-generational studies of the academic profession can look beyond productivity by career stage. For example, Jung (2014) looked at four generations ("fledgling", "established", "maturing", and "patriarch"), and Shin et al. (2015) referred to three generations ("academic boomers", "sandwich generation", and "new generation").

The opportunities for Polish scientists to collaborate internationally prior to the collapse of Communism in 1989 and after it differed substantially for both younger and older cohorts of scientists in these periods (see Najduchowska and Wnuk-Lipińska 1990 about the 1980s; Wnuk-Lipińska 1996 about the 1990s; and Kwiek 2017 about the 2000s). These scientists' careers were clearly affected by events occurring at the time their cohorts graduated and beyond, as the Communist and then postcommunist worlds were disintegrating. The international opportunities were restricted by wider politics and a lack of research funding in the 1980s and by a lack of research funding and new, readily available teachingfocused revenue generation by scientists and their institutions in the 1990s and 2000s. Then the opportunities were widely open in the 2010s, with revised research policies powerfully supporting internationalization in research (Kwiek and Szadkowski 2018; Antonowicz et al. 2017) for all academic cohorts. In other words, in Poland as elsewhere, "success in science depends, in part, on things outside of the control of the individual scientist" (Stephan and Levin 1992: 4).

There is a simple explanation for senior and older academics' higher propensity to collaborate internationally. A study of 19 countries found that internationalists have "more power, better networks, and longer experience" (Jung et al. 2014: 214) and that senior positions entail more resources in terms of "power, prestige, visibility, and scientific standing" (Rostan 2015: 257). Younger academics may also have less success in collaborating internationally because this is more expensive than national or intra-institutional collaboration, although for the same 19 countries, Rostan et al. (2014: 129) reported that the oldest generation of scientists are an exception to this rule. International research collaboration is becoming increasingly common among younger generations. As one recent study showed, collaboration in Norwegian research universities increased from 58\% in 1992 to $66 \%$ in 2001 , and to $71 \%$ in 2013 . Not only are younger generations more internationalized, but almost all generations become increasingly involved in international research collaboration as they age (Kyvik and Aksnes 2015: 1448-1449). As Kwiek's (2019) cross-generational European comparison showed, the oldest generations account for the highest share of 
scientists collaborating with international research partners. In the 11 countries studied, the youngest academic cohort never represented the highest share of internationally collaborating scientists. This is perhaps unsurprising, as international collaboration in research needs time to develop, as well as access to funding (Jeong et al. 2014).

Just as some generations become more productive as they age, some generations are more likely to collaborate as they age. This is clearly linked to changing job market conditions over time, as competition for university jobs waxes and wanes. In more competitive times, only young scientists who are more productive and more internationalized from the very beginning are likely to be employed in the university sector. (On the role of time and place in academic careers, see especially Stephan and Levin 1992; on the impact of cohort effects, see Stephan 2012). Different current generations of scientists were also socialized within "different narratives about higher education's mission, objectives, and role in society" (Santiago et al. 2015: 1474). These narratives would differ in their emphasis on productivity and on international collaboration and publishing.

As Kyvik and Aksnes (2015: 1448) clearly demonstrated for scientists who were the youngest age cohort in 1989-1991, some generations excel in international collaboration over time and as they age. As defined by the survey instrument and sample (e-mail addresses of all academics listed in the national database), younger and older Polish academics are a textbook example of this. Career opportunities and academic norms differed significantly for those entering the academic labor force prior to 1989 and for those who came after (Kwiek 2017). Generally, international research collaboration in Poland under Communism was heavily restricted. Specifically, research-related international travel was focused on the Warsaw Pact countries. Survey-based studies from the period show that, from a cross-generational perspective, $84 \%$ of full professors from the Polish university sector in 1984 traveled for research purposes to socialist countries and $87 \%$ traveled to Western European countries in the previous years. The respective rates for assistant professors were about half as high ( $40 \%$ and 39\%, respectively; the rate for all academic positions was 59\%) (Najduchowska and Wnuk-Lipińska 1990: 81). About a decade later (in 1993), both types of professors were traveling considerably less often to former socialist countries, and their most frequent destination in research collaboration was Western Europe (WnukLipińska 1996: 145). No other studies about the scope of international research collaboration for the 1980s, 1990s, and 2000s are available. Polish universities in the early 1990s were highly selective in employing young scientists. However, as the Polish higher education system began to expand (from 0.4 million students in 1989 to 1.95 million students in 2006), its selectivity dropped significantly. Average individual productivity, research orientation, and involvement in international research collaboration diminished. Prevailing academic norms also differ between those entering the profession before and after the reforms of the 2010s (Kwiek and Szadkowski 2018).

From about 2010, new entrants to the profession have been considerably more researchoriented compared with their older (but not the oldest) colleagues. The new entrants are also more inclined to publish internationally. Polish scientists in general resisted pressures to publish internationally until the recent wave of reforms in 2018-2019, which scheduled a revised research assessment exercise for 2021 and selected 10 additionally funded research universities for a new excellence initiative (2020-2026). The international collaboration imperative was translated into the rules of research assessment at individual and institutional levels and the rules in the acquisition of competitive research funding from the National Research Council (NCN). In the specific Polish case, the academic survivors from the cohort of young scientists in the mid-1990s are predominantly internationalists today. Even though they had to cope with unprecedented challenges in research 
internationalization while working in the 1990s and 2000s, with scarce research funding and the general deinstitutionalization of the research mission in Polish universities linked to their overwhelming teaching-focus (Kwiek 2012), these scholars are more engaged in international research collaboration than the younger, technology-savvy cohorts (as we show in Section "Internationalists: an overview").

\section{International research collaboration by academic field}

Numerous studies (e.g., Cummings and Finkelstein 2012: 103; Rostan et al. 2014: 122-123; Vabø et al. 2014, Finkelstein and Sethi 2014; Aksnes et al. 2019) have reported a strong correlation between academic field and patterns of international collaboration. Using a predictive model based on data from 19 countries, Finkelstein and Sethi (2014) reported that scientists in "hard" fields were 2.3 times more likely to be highly internationalized than those in "soft" fields. As well as discipline, nationality contributes to scientists' motivation and opportunity to engage in international activities (Finkelstein and Sethi 2014: 235). Pressure to publish internationally is also higher in hard fields, and an emphasis on publishing through "proper scientific channels" further intensifies international collaboration (Kyvik and Aksnes 2015). Scientists in the physical sciences and mathematics cluster are by far the most internationalized across 11 European systems, with $76.2 \%$ collaborating internationally, and those in the cluster of professions to be the least internationalized (53.3\% or about a half of them (Kwiek 2015a: 347-348). Aside from differences among national and international disciplinary communities, collaboration pressures also differ by department and institution (highest in research-intensive universities and lowest in teaching-focused institutions) (Kwiek 2019).

\section{International research collaboration and research productivity}

Over the last few decades, the themes of international research collaboration and research productivity have been widely examined in survey-based, interview-based, and bibliometric studies. One significant limitation of survey-based data from the $600 \mathrm{CAP} / \mathrm{EUROAC}$ studies is that they cannot determine the relative impact of international collaboration beyond quantifiable gains in productivity because the survey instrument did not incorporate journal names and citations (Rostan et al. 2014). In his study of highly productive academics across 11 European systems, Kwiek (2016: 388-393) showed that, among statistically significant individual variables, "internationalization and collaboration" emerges as the single most important predictor of research productivity. More specifically, three variables ("collaborating internationally," "publishing in a foreign country," and "research international in scope or orientation") at least double the odds of becoming a top performer (i.e., in the upper $10 \%$ of research productivity).

In the case of Polish top performers in STEM disciplines, international collaboration increases the odds of entering this class by a factor of seven. Along with "publishing abroad," this emerges as the most important variable in the logistic regression model; both are more powerful predictors than "research orientation" and "time spent on research," the two traditional predictors of high productivity (Kwiek 2018b: 443). As shown elsewhere, international research collaboration is correlated with a substantially higher number of publications in all 11 countries studied and in all academic clusters (Kwiek 2015a: 350). While the relationship between productivity and collaboration is not necessarily causal, 
more productive scientists are certainly more internationally visible and therefore potentially more attractive partners for international collaboration. One study of Italian scientists concluded that both research productivity and average quality of output impact positively on international collaboration. Volume of international collaboration is positively correlated with productivity, which in turn impacts intensity of international collaboration and average publication quality (Abramo et al. 2011a: 642).

As to whether more collaborative scholars are more productive, the evidence is mixed, especially when using fractional counting (Abramo et al. 2017), and collaboration rates differ significantly across countries and disciplines (Thelwall and Maflahi 2019; Fox et al. 2017). In general, more productive scientists tend to collaborate more with international colleagues, and the most productive or top performers are much more internationalized than their lower-performing colleagues (Kwiek 2019: 23-71). However, while research performance is directly correlated with intensity and propensity for international collaboration, there is no evidence of the reverse (Abramo et al. 2011b).

\section{International research collaboration, working time, and academic role orientation}

As opposed to research productivity, working time distribution and academic role orientation (i.e., teaching or research) have rarely been studied in the context of international research collaboration. In productivity research, high research time investment (and low teaching time investment), high research role orientation (and low teaching role orientation), and research that is international rather than national in scope and character are correlated with high research productivity (Cummings and Finkelstein 2012: 100-101; Kwiek 2019: 167-197). Both themes have been widely explored in survey-based studies, which are the only means of examining such academic behaviors and attitudes in detail. However, to the best of our knowledge, no published study to date has compared internationalists and locals in terms of working patterns and role orientation. In 19 countries studied, Finkelstein and Sethi (2014: 253) found that faculty who were primarily teaching-oriented were only half as likely to be internationalists, and that collaborating scientists were primarily research-oriented.

\section{International versus national research collaboration}

The link between national and international collaboration is rarely discussed. These two patterns of collaboration differ by career stage, in that junior scientists are more internationally collaborative than their seniors (Shin et al. 2014: 191). The "collaborating domestically" variable does not feature in logistic regression analyses of high research productivity in any European country other than the United Kingdom (Kwiek 2016: 392), where it increases the odds of becoming a top research performer by more than a factor of four. It can be assumed that national collaboration decreases as international collaboration increases in what can be termed a "crowding out effect." Alternatively, scientists who are highly collaborative internationally may also be highly collaborative nationally and institutionally. Bibliometric studies can measure these correlations at the individual level, comparing internationalists and locals by academic field and gender at both institutional and country level, depending on the available data. 


\section{International research collaboration: individual versus institutional predictors}

Finally, survey-based studies have also explored individual and institutional predictors of high research internationalization and the relationship between various dimensions of internationalization and various productivity types. Using self-declared data on internationalization activities, logistic regression analyses show that, at institutions where individual faculty drive internationalization, academics are more likely to be "internationalists" than those at institutions where international linkages are established by administrators (Finkelstein and Sethi 2014: 253). In a study of high research performance, individuallevel predictors were much stronger than institution-level predictors (Kwiek 2016: 392). Examples include survey-based logistic regression studies to study international research collaboration using both individual and organizational independent variables (e.g., Rostan et al. 2014; Finkelstein and Sethi 2014; Cummings and Finkelstein 2012). In general, these concluded that individual variables are far more important than organizational variables in predicting international research collaboration.

\section{Research hypotheses}

Based on previous survey-based and bibliometric research on international research collaboration, combined with previous research on Polish higher education and research sectors, nine working hypotheses were tested in this study.

H1: Gender hypothesis Internationalists tend to be male rather than female.

H2: Age and academic seniority hypothesis Internationalists tend to be older and occupy higher academic positions.

H3: Academic field distribution hypothesis Internationalists tend to come from hard rather than soft science fields.

H4: Domestic collaboration hypothesis Internationalists tend to collaborate domestically more often than locals.

H5: Productivity hypothesis Internationalists are more productive than locals.

H6: Working time distribution hypothesis On average, internationalists work longer hours and spend more time on research, less time on teaching, and more time on administration.

H7: Academic role orientation hypothesis Internationalists are more research-oriented than locals.

H8: Individual predictors hypothesis Individual predictors of being an internationalist are more important than organizational predictors.

H9: Productivity type hypothesis Dimensions of internationalization differ in their impact on different productivity measures. 


\section{Polish higher education: a short profile}

Until about 2009, Polish universities remained largely unreformed following fundamental changes in 1989. Core features of the system-relatively non-competitive funding modes, strongly collegial governance, and a complicated multi-level system of academic degrees and careers-remained largely untouched until the early 2010s (for more detail, see Kwiek and Szadkowski 2018). Since the 2000s, research output has been assessed, benchmarked, and linked to public funding levels - at the aggregate level in the case of basic academic units and at the individual level for project-based research funding. Research grants are now competition-based, and public subsidies for teaching and research depend on academic unit performance relative to other units. There is quasi-market resource allocation for academic units (and, from October 1, 2019, for academic disciplines within each university), involving competition for a fixed amount of annual funding. Detailed points-based bibliometric assessments of individual academics and academic units linked to a ministerial ranking of academic journals increasingly determine the available financial resources.

Poland is gradually implementing a performance-based research funding system (Kulczycki et al. 2017). Funding is linked either directly to prior research outputs (through subsidies allocated to individual academic units rather than to institutions) or indirectly in the form of grant-based competitive funding for academics. The ongoing changes center on competitive project-based funding from the national research council (NCN).

Since 2010, the formula for the distribution of research funding has changed gradually, with institutional "haves" receiving more of the available competitive research funding. In other words, the new funding mechanisms fuel vertical stratification and the gradual emergence of two opposing institutional "families": those that are strongly or moderately research-oriented and those with no research mission or funding. Additionally, the new Excellence Initiative-Research Universities will provide additional funding (accounting for $10 \%$ of total subsidies received in 2018) to 10 major universities and technical universities (selected in October 2019) for the period 2020-2026.

Despite these ongoing changes, the Polish science system remains heavily underfunded in Western European terms. According to Main Science and Technology Indicators (OECD 2019), Poland's Gross Domestic Spending on R\&D (GERD) in 2017 as a percentage of Gross Domestic Product (GDP) was the fourth-lowest in the European Union (at 1.03 as compared to 1.97 for EU-28 countries and 2.37 for OECD countries). Poland's Higher Education Expenditure on R\&D (HERD) as a percentage of GDP also remains among the lowest in the European Union. The low levels of public and private investment in R\&D are reflected in publication, citation, and international collaboration data for the period 2009-2018 (Scopus 2020). The limitations of both Web of Science (WoS) and Scopus datasets are widely discussed in the literature; specifically, the two datasets do not cover publications in Polish, still prevalent in Polish social sciences and humanities. A recent report based on 120,111 articles published in 2013-2016 highlights that only $25.1 \%$ of academics in economics, $41.1 \%$ in social sciences, and $55.5 \%$ in law had any publications in English in this period (Kulczycki 2019: 26). However, while national datasets include multiple publication formats (which are also used in further analyses), for cross-national comparative purposes about the scope of international collaboration, Scopus is generally very useful.

In 2018, total Polish publication output (all types in Scopus) was about 51,000, with 34,200 articles $(5.59 \%$ of the total output of 28 European Union member states, increasing by more than a half within a decade, from about 22,000 in 2009). Poland's share of internationally co-authored articles is the lowest in the EU-28. Although this increased 
from $29.1 \%$ in 2009 to $35.8 \%$ in 2018 , the EU-28 average was $45.7 \%$ in 2018 . While the figure almost doubled during this period (from about 6400 to about 12,300), it remained relatively small at just $4.38 \%$ of the EU-28 figure (up from $3.93 \%$ in 2009). In terms of Field-Weighted Citation Impact (FWCI), Poland has struggled to achieve the world average of 1.0, which it reached only in the last 3 years (FWCI 2018: 1.02). On a more positive note, Poland's average international collaboration impact for 2009-2018 roughly matches the average for EU-13, EU-15, and EU-28 countries. In short, Polish scientists' publication patterns differ substantially from those in major Western European science systems. This is changing, but slowly. A decade ago, Poland and Romania had the lowest rates of internationally co-authored publications, and this remains the case today.

Analysis of Polish science's level of internationalization in the period 2009-2018 confirms the almost complete inefficiency of the higher education reforms introduced over the last decade. The structure of publications indexed in the Scopus database has remained almost unchanged for a decade, and although research internationalization is a key element of the recent reforms, growth is extremely slow. Polish science exhibits high levels of national research collaboration (25.4\% in 2018), yet the only large European countries where this level is increasing are Poland and Romania. Polish science is also characterized by a high level of intra-institutional collaboration $(28.1 \%$ ) - that is, publications whose authors are affiliated to the same institution. In 2018, this figure exceeded $25 \%$ in only three European countries: Poland, Lithuania, and Slovakia (see a comparative analysis of 28 European system in 2009-2018 in Kwiek 2020).

In the context of Polish reforms, increasing the intensity of international research collaboration is by far the best way to increase the global visibility of national research. Only scientific collaboration that is intensive, long-term, and consistently subsidised by the state (at both institutional and individual levels) can facilitate the gradual transition of Polish science from the periphery to the center of European research. As part of the 2009-2011 wave of reforms, Poland explored ways of distributing research funding, but the level of public expenditure remained low. As such, Polish science is among Europe's most resource-poor systems, and the low levels of international research collaboration discussed here are a direct consequence of this low level of public investment.

Researchers cooperate with colleagues from abroad primarily because it pays off scientifically for them. By cooperating and publishing more internationally and less with colleagues from their own institutions, the incentives for international collaboration become stronger than for intra-institutional collaboration. However, the data show that the situation in Poland over the last decade has been exactly the opposite; existing mechanisms (and the available research funding) have promoted intra-institutional collaboration at the expense of international collaboration. Consequently, Poland is joint first in Europe (with Lithuania) in terms of intra-institutional collaboration and co-authorship and last in terms of the international collaboration that is crucial for globalized scientific development.

\section{Data and methods}

\section{Defining internationalists}

Internationalists in Polish universities are clearly defined as academic scientists who collaborate in research with their international colleagues. Collaborating with international research colleagues may indicate different levels of international mobility and co-authorship (from 
intense to none). For present purposes, internationalists are contrasted with locals-academic scientists who do not collaborate with international research colleagues. In the survey, the questions pertaining to international research collaboration were formulated as follows. "How would you characterize your research efforts during this (or the previous) academic year? Do you collaborate with international colleagues?" (Yes/No) (Question D1/4). No explanation or guidance was provided in relation to the terms collaborate, international, or research. "Polish scientists" were defined by their affiliations, following the survey instrument and the sample used, as all scientists listed in the official national registry of scientists employed in Polish higher education institutions from which e-mail addresses were drawn, regardless of their citizenship.

\section{Dataset}

The data were sourced from the European Academic Profession: Responses to Societal Challenges (EUROAC) study, which is a sister project of the global Changing Academic Profession (CAP) study (see Carvalho 2017 for a recent overview of the CAP/EUROAC family). The final dataset, dated June 17 2011, was created by René Kooij and Florian Löwenstein from the International Centre of Higher Education and Research-INCHERKassel. The response rate in Poland (11.22\%) was similar to those in studies of the academic profession in several countries over the last decade.

Survey respondents marked one of twenty one disciplines (as officially defined by the Central Committee for Academic Degrees and Titles in its act of October 24, 2005). Academics were grouped in eight clusters of academic disciplines, or eight academic fields in the Polish classification-humanities and arts (HUM), social sciences (SOC), physical sciences and mathematics (PHYSMATH), life sciences (LIFE), engineering and technical sciences (ENGITECH), agriculture (AGRI), medical sciences and health-related sciences (MEDHEALTH), and other disciplines (like fine arts) — that best represented the structure of the Polish academic profession. The grouping was determined by the regulation of the Ministry of Science and Higher Education of August 11, 2011 on the classification of areas, fields, and disciplines: the eight clusters represent eight major academic fields.

The total number of valid responses (those answering at least $50 \%$ of questionnaire items) was 3704; non-responses occurred at both item and unit (person) level, and item nonresponses differed significantly. As the final analysis excluded scientists from "other" disciplines, those employed in the postdoctoral position of docent, those who did not answer the question about international collaboration in research, and those whose work contract did not involve research, 2453 observations from seven major discipline clusters were included: 1172 from internationalists (51.4\%) and 1107 from locals (48.6\%), see Table 1.

\section{Sampling}

Stratified random sampling was used to ensure that the resulting sample was distributed in the same way as the target population (Hibberts et al. 2012: 61-62; Bryman 2012: 192-193). A stratified sampling frame was created, using two criteria: gender and academic position. (The description of sampling, instrument, data collection, and limitations draw on a parallel Scientometrics paper on Polish top performers; Kwiek 2018b: 421-425.) Stratification of the sample mirrored that of the population on the specified criteria and mirrored a simple random sample in all other ways. Random sampling was subsequently used to obtain elements from each stratum. Members of the target population were identified by accessing a national ministerial database of all Polish academic scientists. 
Table 1 Distribution of the sample population. Internationalists = scientists collaborating internationally in research (Yes)

\begin{tabular}{|c|c|c|c|c|c|c|c|}
\hline & All $(n)$ & $\begin{array}{l}\text { Research- } \\
\text { involved } \\
\left(n_{\mathrm{RI}}\right)\end{array}$ & $\begin{array}{l}\% \\
\text { Research- } \\
\text { involved }\end{array}$ & $\begin{array}{l}\text { Internation- } \\
\text { alists } \\
(\mathrm{INT}) \\
\left(n_{\mathrm{I}}\right)\end{array}$ & $\begin{array}{l}\text { Locals } \\
\text { (LOC) } \\
\left(n_{\mathrm{L}}\right)\end{array}$ & $\begin{array}{l}\text { Internation- } \\
\text { alists } \\
(\mathrm{INT}) \% \\
\left(n_{\mathrm{I}}\right):\left(n_{\mathrm{L}}+n_{\mathrm{I}}\right)\end{array}$ & $\begin{array}{l}\text { Locals (LOC) } \\
\% \\
\left(n_{\mathrm{L}}\right):\left(n_{\mathrm{L}}+n_{\mathrm{I}}\right)\end{array}$ \\
\hline HUM & 566 & 561 & 99.1 & 251 & 271 & 48.1 & 51.9 \\
\hline SOC & 263 & 257 & 97.9 & 86 & 151 & 36.3 & 63.7 \\
\hline PHYSMATH & 191 & 190 & 99.7 & 144 & 39 & 78.7 & 21.3 \\
\hline LIFE & 417 & 415 & 99.5 & 256 & 148 & 63.4 & 36.6 \\
\hline ENGITECH & 557 & 554 & 99.5 & 256 & 264 & 49.2 & 50.8 \\
\hline AGRICULT & 176 & 174 & 99.3 & 62 & 95 & 39.5 & 60.5 \\
\hline $\begin{array}{l}\text { MED- } \\
\text { HEALTH }\end{array}$ & 284 & 279 & 98.3 & 117 & 139 & 45.7 & 54.3 \\
\hline Total & 2453 & 2430 & 99.1 & 1172 & 1107 & 51.4 & 48.6 \\
\hline $\begin{array}{l}\text { Soft com- } \\
\text { bined* }^{*}\end{array}$ & 829 & 818 & 98.7 & 337 & 422 & 44.4 & 55.6 \\
\hline $\begin{array}{l}\text { Hard com- } \\
\text { bined }\end{array}$ & 1624 & 1612 & 99.3 & 835 & 685 & 54.9 & 45.1 \\
\hline
\end{tabular}

Only scientists employed full-time in the university sector and involved in both teaching and research were included. (This applies to all figures and tables.)

* "Soft combined" fields represent all disciplines grouped in the HUM and SOC clusters, and "hard combined" fields - all disciplines grouped in the PHYSMATH, LIFE, ENGITECH, AGRICULT, and MEDHEALTH disciplines, as classified in the Polish classification of disciplines from 2011

At the time of the survey, the target population to which the results were to be generalized included 83,015 scientists employed full-time in the public sector (43.8\% female and $56.2 \%$ male, including 17,683 full and associate professors (21.3\%), 36,616 assistant professors (44.1\%), 10,784 assistants (13.0\%), and 15,013 senior lecturers and lecturers (18.1\%) (GUS 2011: 308-309). Private sector scientists were excluded because the sector is fully teaching-focused.

The sample of Polish scientists was representative of the target population on the two strata of gender and academic rank and included $45.2 \%$ female scientists and 54.8\% males; $22.6 \%$ full and associate professors, $42.1 \%$ assistant professors, $10.9 \%$ assistants, and $24.4 \%$ senior lecturers and lecturers. There was no sampling bias; no members of the sampling frame had nil or limited chances of inclusion in the sample; and no group of scientists was systematically excluded from the sampling frame (Bryman 2012: 187). However, as it is impossible to determine to what extent the pool of respondents differed from the pool of non-respondents, there remains a possibility of non-response bias (Stoop 2012: 122), and no subsequent survey was conducted to ask non-responders why they did not participate.

\section{Instrument and data collection}

The survey was performed by the National Information Processing Institute (OPI). An invitation to participate in the web-based survey, with individually coded identifier, was sent in June 2010 to 33,000 scientists - that is, all scientists whose e-mail addresses were available - at national level. This narrowed the target population to the sampling frame, with an inevitable coverage error. There was no pre-notification e-mail, and two reminders were 
sent electronically between June 1, 2010 and July 20, 2010. Full anonymity was assured in the invitation, and reminders were sent only to non-respondents, using the assigned identifiers. Web-based surveys tend to incur a specific non-response bias due to lack of internet access (although this is likely to be smaller for academics, who routinely use both e-mail and internet). The questionnaire was pilot tested by outside parties, who reviewed the format and wording and structure of individual items, in May 2010.

In seeking to contrast research internationalists and locals, there is a trade-off between the advantages of using self-reported survey data and publication numbers as the only measure of research performance and the use of a combination of publications, citations, $\mathrm{H}$-index, and other bibliometric measures. Detailed individual-level data-including data on international research collaboration rather than the international publication co-authorship proxy-depend on the use of a survey instrument.

\section{Methodological strengths and limitations}

The analyses are based on self-declared data, provided voluntarily by Polish scientists. The chosen measure of research productivity was the number of peer-reviewed articles (and peerreviewed article equivalents) published during a three-year reference period. To varying degrees, respondents "may present an untrue picture to the researcher, for example answering what they would like a situation to be rather than what the actual situation is" (Cohen et al. 2011: 404). Although self-reported publication data are not perfect, they do not seem to entail systematic error (that is, errors are random) or systematic bias (which occurs when errors tend to be in one direction more than another). The survey instrument did not distinguish between different tiers of academic journals and, unfortunately, did not permit study of citation patterns. Journal impact factor and number of author citations were beyond the scope of this survey. As a consequence of data anonymization, individual research productivity could not be linked to individual institutions beyond the six major institutional types and could not be linked to large databases providing citation details (such as Scopus).

To strengthen the robustness of the analyses (see also Kwiek 2018b, 2019), a study of articles was supplemented with a study of article equivalents - to be able to include books, until recently massively published in a specific Polish context. Three measures were used in addition to peer-reviewed articles (PRA): peer-reviewed article equivalents (PRAE), internationally co-authored peer-reviewed article equivalents (IC-PRAE), and English language peer-reviewed article equivalents (ENG-PRAE). That is, publication counts were converted into article equivalents. The PRAE measure is calculated as the weighted sum of self-reported articles in books or journals (valued as 1 article equivalent), edited books (valued as 2 article equivalents), and authored books (valued as 5 article equivalents) published over the three-year reference period. This follows the procedure used in Piro et al. (2013: 309), Rørstad and Aksnes (2015: 319), Kyvik and Aksnes (Kyvik and Aksnes 2015: 1443), Bentley (2015: 870), and Gorelova and Lovakov (2016: 11). In most survey-based studies, 4-6 articles equate to one full monograph. However, importantly, the selection of formula used for calculating article equivalents influences the observed publication patterns (Kyvik and Aksnes 2015: 1449).

Following Bentley (2015), a self-reported share of peer-reviewed publications was applied to each observation. The advantage of using the PRAE measure in a cross-disciplinary study is that it captures various publishing outlets, encompassing authored and edited books (which are still a major social sciences and humanities outlet in Poland) as well as articles. The IC-PRAE measure is based on the self-reported share of publications co-authored with 
international colleagues, and the ENG-PRAE measure is based on the self-reported share of publications published in a foreign language, which is predominantly English (for $87.1 \%$ of Polish scientists). While the IC-PRAE measure refer to collaboration type (internationally co-authored publications imply a degree of collaboration), the ENG-PRAE measure refers only to the language of publications, regardless of their type. Consequently, no distinction is made between "national" and "international" publications in this study. The survey therefore asked combined questions about number of scholarly contributions and percentage of peer-reviewed publications, English-language publications, and internationally co-authored publications. It did not ask, however, about the share of single-authored or non-collaborative publications; considering that more than a half of Polish scientists do not publish in Scopusindexed journals, classical bibliometric databases could not be easily used for estimations of their proportions. Only about $20 \%$ of publications by Polish authors are indexed in Web of Science (WoS) or Scopus databases: there are 1,149,304 publications in the Polish Scientific Bibliography (PBN) registered for 2013-2018, of which only 243,522 (21.17\%) are indexed in WoS and 271,818 (23.65\%) are indexed in Scopus. Consequently, the publication patterns from WoS and Scopus cannot be easily transferred to those of all publications by Polish authors. It is worth a reminder that internationalists are contrasted with locals on the basis of their academic activities of (collaborating or not collaborating in research) rather than their publishing patterns (publishing or not publishing internationally; publishing or not publishing in co-authorship with colleagues affiliated with foreign institutions).

The research productivity analyses reported below convert publication counts into article equivalents for fairer comparison of productivity across academic fields in which publication patterns are dissimilar (Kyvik and Aksnes 2015). The PRAE measure was used to facilitate more comprehensive exploration of cross-disciplinary differences in publication patterns between top performers and others; the IC-PRAE and ENG-PRAE measures were used to explore how the two groups differed in terms of internationalization. Article equivalents were applied to multi-disciplinary studies involving major clusters of disciplines rather than to science, technology, engineering, and mathematics clusters alone. Article equivalents have been used in Scientometrics and Journal of Informetrics studies (e.g., Kyvik 1989: 206; Piro et al. 2016: 945; Bentley 2015: 870; Rørstad and Aksnes 2015: 319). The use of PRA and PRAE measures reflects the particularity of the Polish system, which has traditionally supported the production of books across all academic fields.

\section{Other limitations}

One of the present study's limitations is that the survey instrument could not distinguish different nationalities (countries), locations (institutions and departments), intensities (high to low), and modes of contact (e.g., face-to-face/conference/e-mail) in international research collaboration. Instead, international research collaboration as a behavioral concept was measured as a crude Yes or No, and different individual perceptions of internationalization in research were amalgamated and averaged. A second limitation is that Polish scientists could not be compared across institutions-for example, the study does not illuminate differences between scientists from prestigious institutions (especially the flagship institutions, the University of Warsaw and Jagiellonian University; see Kwiek and Szadkowski 2018) and those of lower academic standing. A further limitation relates to the structure of the dataset; as no distinction could be drawn between single-author and multiple-author publications only total counts were possible. The same was true of national and international publications, beyond the use of proxies ("internationally co-authored publications" 
and "publications in English"). Finally, the cross-sectional dataset made it impossible to compare research internationalization across academic generations. Despite these limitations, it was possible to test the working hypotheses and to arrive at valid conclusions.

\section{Research results}

\section{Internationalists: an overview}

H1: Gender hypothesis Internationalists tend to be male rather than female.

Frequencies of the selected demographic characteristics of internationalists are listed in Table 2. Unsurprisingly (in light of existing evidence on gender in international research collaboration) (Ackers 2008; Fox et al. 2017; Kwiek and Roszka 2020; Abramo et al. 2013), male scientists are more internationalized than female scientists; a majority of male scientists (56.0\%) are internationalists as compared to $45.0 \%$ of females. Gender differences are field-sensitive, with a higher percentage of female internationalists in hard academic fields. As the gender difference is statistically significant (which has powerful policy implications in terms of internationalization as a stratifying force in the academic profession), Hypothesis 1 is supported.

H2: Age and seniority hypothesis Internationalists tend to be older and occupy higher academic positions.

Internationalization in research in Poland is an older scientist's game, increasing with age, academic experience, academic degree, and academic position (Table 2). First, internationalization clearly increases with age; internationalists are a minority in the 30-39 age group but a majority in older age brackets. Second, internationalization clearly increases with academic experience; while a minority of scientists with less than 20 years of experience are internationalists, a majority of those with at least 20 years of experience are internationalists, with the highest share in the oldest age group. (Academic experience refers to years of full-time employment in the higher education sector beyond teaching and/ or working as a research assistant.) Finally, internationalization increases with academic degree level and academic position; a minority of PhD-only scientists and assistant professors (where $\mathrm{ahD}$ is prerequisite for habilitation and habilitation is prerequisite for professorship) are internationalists as compared to two-thirds of scientists with professorships and those employed as ordinary professors. In this sample, the mean age of internationalists was 47.5 years, and their mean academic experience and institutional experience (i.e., employment by the same institution) were 20.9 years and 18.6 years, respectively.

Polish internationalists therefore align with known patterns (Rostan and Ceravolo 2015; Rostan et al. 2014; Shin et al. 2014); in general, internationalization is lower among younger generations and higher among older generations. Across all age brackets, the highest levels are in the physical sciences and mathematics, and the lowest are in social sciences (Kyvik and Larsen 1997; Smeby and Gornitzka 2008) (see Fig. 1). The distribution of Polish scientists across academic clusters corresponds roughly to their distribution in the higher education system. (The tiny Polish Academy of Science was excluded from this survey.) The share of internationalists increases with academic position across all disciplines, 
Table 2 Sample description: frequencies of selected demographic characteristics

\begin{tabular}{|c|c|c|c|c|c|c|c|}
\hline & & \multirow{2}{*}{\multicolumn{2}{|c|}{$\begin{array}{l}\text { International- } \\
\text { ists } \\
\text { (INT) }\end{array}$}} & \multicolumn{2}{|c|}{ Locals } & \multicolumn{2}{|l|}{ Total } \\
\hline & & & & \multicolumn{2}{|c|}{ (LOC) } & & \\
\hline & & \multicolumn{2}{|c|}{$N=1151$} & \multicolumn{2}{|c|}{$N=1090$} & \multicolumn{2}{|c|}{$N=2241$} \\
\hline & & $N$ & $\%$ & $N$ & $\%$ & $N$ & $\%$ \\
\hline \multirow[t]{2}{*}{ Gender } & Male & 722 & $56.0^{*}$ & 566 & 44 & 1288 & 57.5 \\
\hline & Female & 429 & 45 & 524 & $55.0 *$ & 953 & 42.5 \\
\hline \multirow[t]{5}{*}{ Age group } & under 30 & 21 & 56.1 & 17 & 43.9 & 38 & 1.7 \\
\hline & 30 to 39 & 368 & 45.4 & 443 & $54.6^{*}$ & 812 & 36.1 \\
\hline & 40 to 49 & 273 & 48.1 & 294 & 51.9 & 566 & 25.1 \\
\hline & 50 to 59 & 262 & $59.9 *$ & 175 & 40.1 & 437 & 19.4 \\
\hline & 60 and more & 232 & $58.3 *$ & 167 & 41.7 & 399 & 17.7 \\
\hline \multirow[t]{5}{*}{ Academic experience } & under 10 & 300 & 47.9 & 326 & $52.1 *$ & 627 & 27.7 \\
\hline & 10 to 19 & 280 & 43.8 & 359 & $56.2^{*}$ & 640 & 28.3 \\
\hline & 20 to 29 & 221 & $57.2 *$ & 165 & 42.8 & 386 & 17.1 \\
\hline & 30 to 39 & 255 & $57.6^{*}$ & 188 & 42.4 & 443 & 19.6 \\
\hline & 40 and more & 107 & $64.6^{*}$ & 59 & 35.4 & 166 & 7.3 \\
\hline \multirow[t]{7}{*}{ Academic field } & HUM & 251 & 48.1 & 271 & 51.9 & 522 & 22.9 \\
\hline & SOC & 86 & 36.3 & 151 & $63.7 *$ & 238 & 10.4 \\
\hline & PHYSMATH & 144 & $78.6^{*}$ & 39 & 21.4 & 183 & 8 \\
\hline & LIFE & 256 & $63.3^{*}$ & 148 & 36.7 & 404 & 17.7 \\
\hline & ENGITECH & 256 & 49.3 & 264 & 50.7 & 519 & 22.8 \\
\hline & AGRICULT & 62 & 39.5 & 95 & $60.5^{*}$ & 157 & 6.9 \\
\hline & MEDHEALTH & 117 & 45.7 & 139 & $54.3^{*}$ & 256 & 11.2 \\
\hline \multirow[t]{2}{*}{ Soft/Hard } & SOFT & 337 & 44.4 & 422 & $55.6^{*}$ & 759 & 33.3 \\
\hline & HARD & 835 & $54.9 *$ & 685 & 45.1 & 1520 & 66.7 \\
\hline \multirow[t]{4}{*}{ Academic degree } & MA/MSc & 33 & 47.3 & 37 & 52.7 & 70 & 3.2 \\
\hline & $\mathrm{PhD}$ & 585 & 43.2 & 769 & $56.8^{*}$ & 1354 & 61.5 \\
\hline & Habilitation degree & 267 & $59.0 *$ & 186 & 41 & 452 & 20.5 \\
\hline & Professorship title & 240 & $73.8 *$ & 85 & 26.2 & 326 & 14.8 \\
\hline \multirow[t]{2}{*}{ Marital status } & Married/in partnership & 975 & 51.7 & 912 & 48.3 & 1887 & 83.8 \\
\hline & Single & 181 & 49.6 & 184 & 50.4 & 365 & 16.2 \\
\hline \multirow[t]{4}{*}{ Academic position } & Instructor (Asystent) & 133 & 42.6 & 179 & $57.4^{*}$ & 311 & 13.6 \\
\hline & Assistant prof. (Adiunkt) & 577 & 45.2 & 698 & $54.8^{*}$ & 1274 & 55.9 \\
\hline & Associate prof. (Prof. ndzw.) & 275 & $62.3 *$ & 167 & 37.7 & 442 & 19.4 \\
\hline & Full professor (Profesor zw.) & 188 & $74.6^{*}$ & 64 & 25.4 & 252 & 11.1 \\
\hline Age & Mean & 1156 & $47.5^{*}$ & 1095 & 45 & 2251 & 46.3 \\
\hline Academic experience 1) & Mean & 1164 & $20.9^{*}$ & 1098 & 18 & 2262 & 19.5 \\
\hline Institutional experience 2) & Mean & 1158 & $18.6^{*}$ & 1089 & 16.1 & 2247 & 17.4 \\
\hline
\end{tabular}

(1) Academic experience refers to number of years since first full-time job (other than research and teaching assistant in the higher education/research sector; Question A6). (2) Institutional experience refers to number of years spent at current institution. ${ }^{*} p<0.05$ 

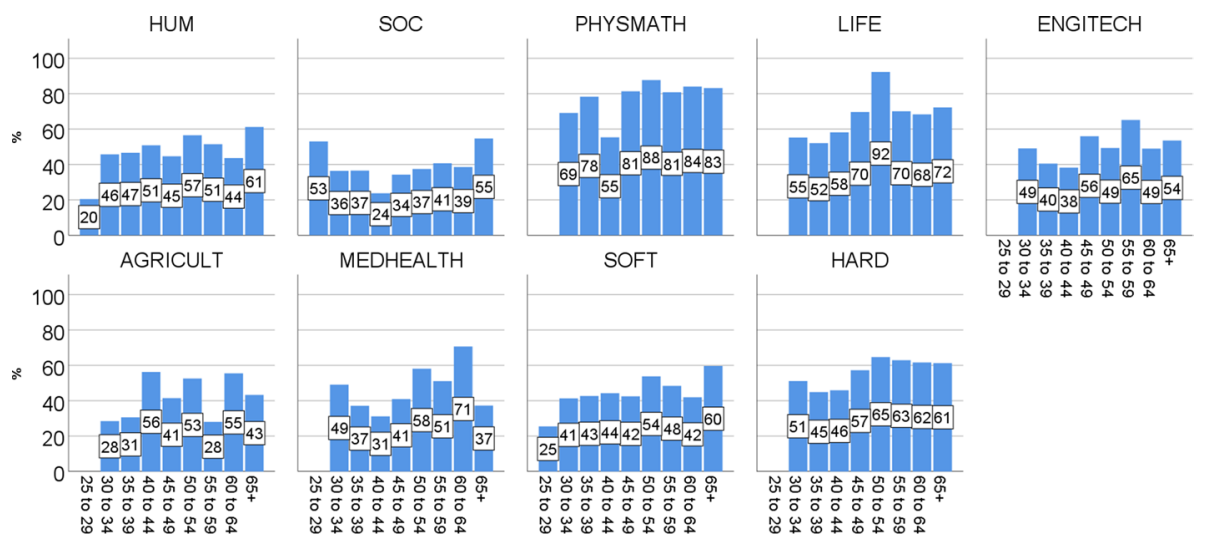

Fig. 1 Internationalists by age group and academic cluster (\%)

both hard and soft. For PhDs in SOC, AGRICULT and MEDHEALTH, the figure is about one-third as compared to two-thirds in PHYSMATH. For habilitation degree holders, the share is lowest in AGRICULT and SOC and highest in PHYSMATH and LIFE. Finally, in the case of professors, eight or nine out of ten in PHYSMATH, LIFE and MEDHEALT are internationalists as compared to about half in SOC and AGRICULT (see Fig. 2). On that basis, Hypothesis 2 is supported.

H3: Academic field distribution hypothesis Internationalists tend to come from hard rather than soft science fields.

The cluster of soft academic fields comprises HUM and SOC while the cluster of hard academic fields comprises PHYSMATH, LIFE, ENGITECH, AGRICULT, and MEDHEALTH. All OTHER fields were removed from the analysis. Internationalization is highly field-sensitive; internationalists comprise only a third of scientists in social sciences

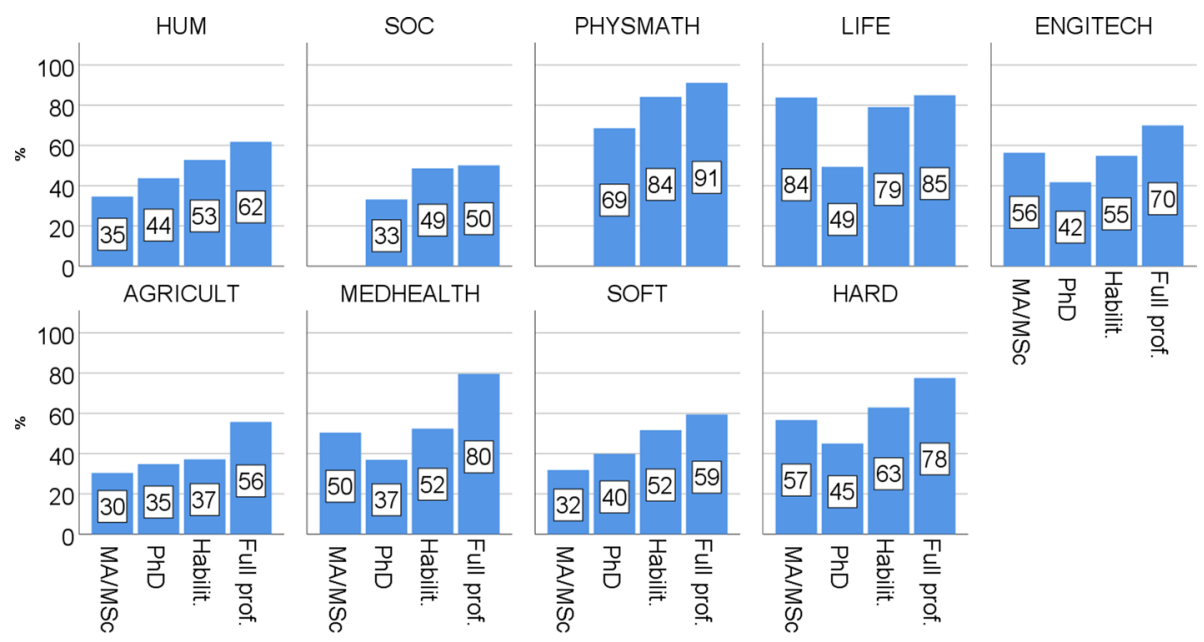

Fig. 2 Internationalists by academic degree and academic cluster (\%) 
Table 3 Scientists reporting collaboration with international colleagues (D1/4) by academic cluster $(\%)$

\begin{tabular}{llll}
\hline & $\begin{array}{l}\text { Yes - } \\
\text { Internationalists }\end{array}$ & $\begin{array}{l}\text { No - } \\
\text { Locals }\end{array}$ & Total \\
\hline HUM & 48.1 & 51.9 & 100 \\
SOC & 36.3 & $63.7^{* * *}$ & 100 \\
PHYSMATH & $78.6^{* * *}$ & 21.4 & 100 \\
LIFE & $63.3^{* * *}$ & 36.7 & 100 \\
ENGITECH & 49.3 & 50.7 & 100 \\
AGRICULT & 39.5 & $60.5^{*}$ & 100 \\
MEDHEALTH & 45.7 & $54.3^{*}$ & 100 \\
Total & $51.4^{* *}$ & 48.6 & 100 \\
Soft combined & 44.4 & $55.6^{* * *}$ & 100 \\
Hard combined & $54.9^{* * *}$ & 45.1 & 100 \\
\hline
\end{tabular}

$* p<0.05 ; * * p<0.01 ; * * * p<0.001$

but more than three quarters in physical sciences and mathematics. As they constitute a minority in soft fields and a majority in hard fields (Table 3), Hypothesis 3 is supported.

H4: Domestic collaboration hypothesis Internationalists tend to collaborate domestically more often than locals.

Polish internationalists also collaborate more often domestically-in other words, international collaboration seems not to exclude collaboration with national peers (D1/3: "Do you collaborate with persons at other institutions in your country?"). Only one in five internationalists (20.5\%) do not collaborate domestically (Table 4). We can only speculate about the reasons for domestic non-collaboration, which may include lack of time for both types of collaboration, lack of funding for domestic collaboration, lower quality of national peers, or limited opportunities to co-publish internationally. Interestingly, only half of locals collaborate domestically - in other words, half of those who do not collaborate internationally

Table 4 Scientists reporting domestic collaboration (D1/3) by academic cluster (\%)

\begin{tabular}{|c|c|c|c|c|}
\hline & \multicolumn{2}{|c|}{ Internationalists (INT) } & \multicolumn{2}{|l|}{ Locals (LOC) } \\
\hline & $\begin{array}{l}\text { Collaborate } \\
\text { domestically }\end{array}$ & $\begin{array}{l}\text { Do not collaborate } \\
\text { domestically }\end{array}$ & $\begin{array}{l}\text { Collaborate } \\
\text { domestically }\end{array}$ & $\begin{array}{l}\text { Do not collabo- } \\
\text { rate domestically }\end{array}$ \\
\hline HUM & $72.1 * * *$ & 27.9 & 36.9 & $63.1 * * *$ \\
\hline $\mathrm{SOC}$ & 75.5 & 24.5 & 36.5 & $63.5 * * *$ \\
\hline PHYSMATH & 74.0 & 26.0 & 46.7 & 53.3 \\
\hline LIFE & $86.7 * * *$ & 13.3 & $71.6^{* * *}$ & 28.4 \\
\hline ENGITECH & 78.2 & 21.8 & $56.8 *$ & 43.2 \\
\hline AGRICULT & $91.7 *$ & 8.3 & $59.8 *$ & 40.2 \\
\hline MEDHEALTH & 85.6 & 14.4 & 48.6 & 51.4 \\
\hline Total & 79.5 & 20.5 & 50.0 & 50.0 \\
\hline Soft combined & $73.0 * * *$ & 27.0 & 36.7 & $63.3 * * *$ \\
\hline Hard combined & $82.1 * * *$ & 17.9 & $58.2 * * *$ & 41.8 \\
\hline
\end{tabular}

${ }^{*} p<0.05 ; * * p<0.01 ; * * * p<0.001$ 
also fail to collaborate domestically. This effect is highly differentiated across fields; about two-thirds of locals in humanities and social sciences do not collaborate domestically-in other words, in soft academic disciplines, the "lonely scholar" model prevails $(63.3 \%$ of locals). The highest share of locals collaborating domestically is in life sciences $(71.6 \%)$.

For all academic fields (Table 5), the percentage of internationalists collaborating domestically is higher than the percentage of locals collaborating domestically. As the results are statistically significant for all fields except social sciences and agriculture, Hypothesis 4 is supported.

\section{Individual research productivity and international collaboration}

H5: Productivity hypothesis Internationalists are more productive than locals.

This hypothesis was tested using the standard measure of number of peer-review articles (PRA) and IC-PRA and ENG-PRA measures to provide a more detailed account. Average research productivity is summarized in Tables 6, 7 and 8, comparing locals (left panel) and internationalists (right panel), by productivity type (PRA, IC-PRA, ENG-PRA) and academic cluster. The present study adopts Teodorescu's (2000: 206) definition of research productivity as the "self-reported number of journal articles and chapters in academic books that the respondent had published in the 3 years prior to the survey." For instance, in line 1, mean PRA for the three-year reference period is 3.2 for all locals and 4.3 for all internationalists in humanities (HUM) cluster; as only $58.3 \%$ of locals and $56.9 \%$ of internationalists actually published, the means are 5.4 and 6.5, respectively, with medians of 3.6 and 6.1 , respectively. The $95 \%$ confidence interval for mean (4.6 articles as a lower bound and 6.2 articles as an upper bound) indicates that the 4.6-6.2 interval covers the number of articles with 95 percent of certainty; similarly internationalists in the humanities produced on average 6.5 articles, with the 5.3-8.5 interval. In the context of 11 European systems studied elsewhere, the average Polish scientist is a low research performer, and their publication outlets are largely national (Kwiek 2016).

As shown in Table 7, international co-authorship of publications is marginal for Polish locals (2.1\%) and higher (but still relatively low) for internationalists (13.8\%). There is clear cross-disciplinary differentiation among internationalists; for PHYSMATH, the share is almost 50\%, and for LIFE and AGRICULT, it is about 40\%. At the other end of the spectrum, humanities and social sciences internationalists fall in the $15-20 \%$ range. The average for soft academic fields is $15.0 \%$ while hard fields average $37.6 \%$.

Finally, as shown in Table 8, about a third of Polish locals publish in English (36.3\%), as compared to $51.7 \%$ of those collaborating internationally. Again, the highest shares are reported for PHYSMATH, with six out of ten (locals and internationalists) publishing in English. In general, Polish internationalists are a world apart from locals in terms of publishing patterns. Additionally, internationalists are strongly differentiated by academic discipline and in particular by the soft/hard split. Internationalists produce more publications and more publications with international colleagues, but there are significant disciplinary variations. Among internationalists in the PHYSMATH cluster, almost $70 \%$ of publications are internationally co-authored; in MEDHEALTH and LIFE clusters, the figure is about $50 \%$ while in the HUM and SOC clusters, it is just above $30 \%$.

Across academic clusters, internationalists (accounting for $51.4 \%$ of all scientists) produce more than $90 \%$ of internationally co-authored publications (Table 9); in PHYSMATH, SOC and LIFE clusters, the share is $97-99.9$ percent. This means that scientists in these 


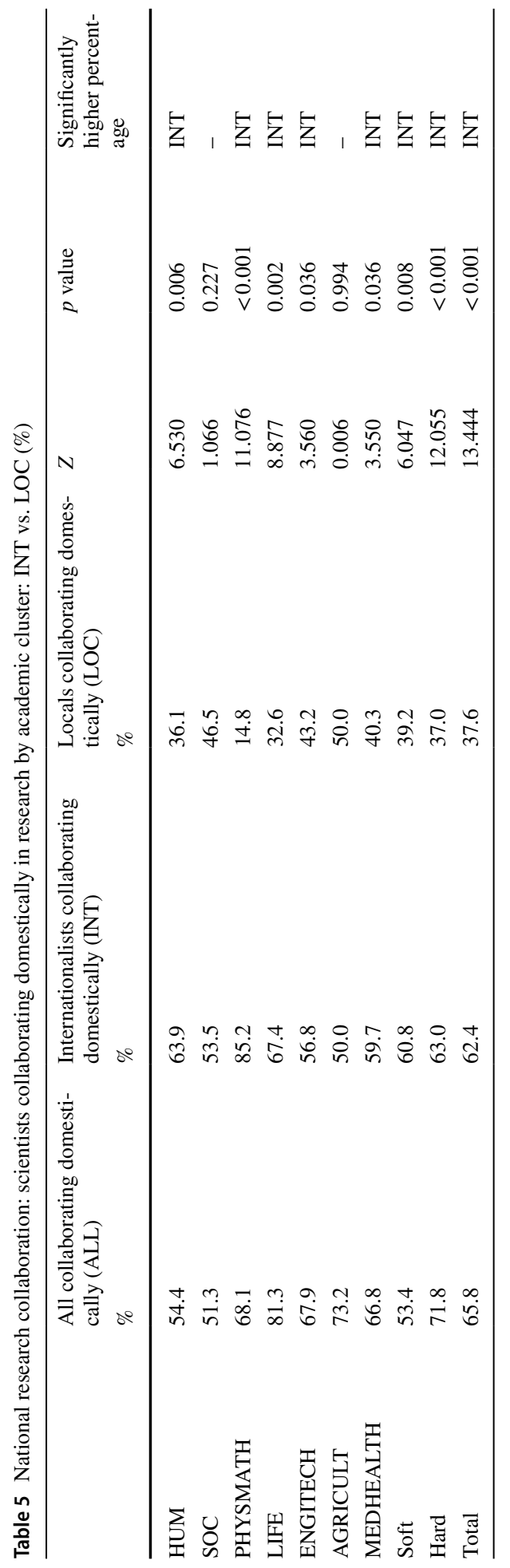




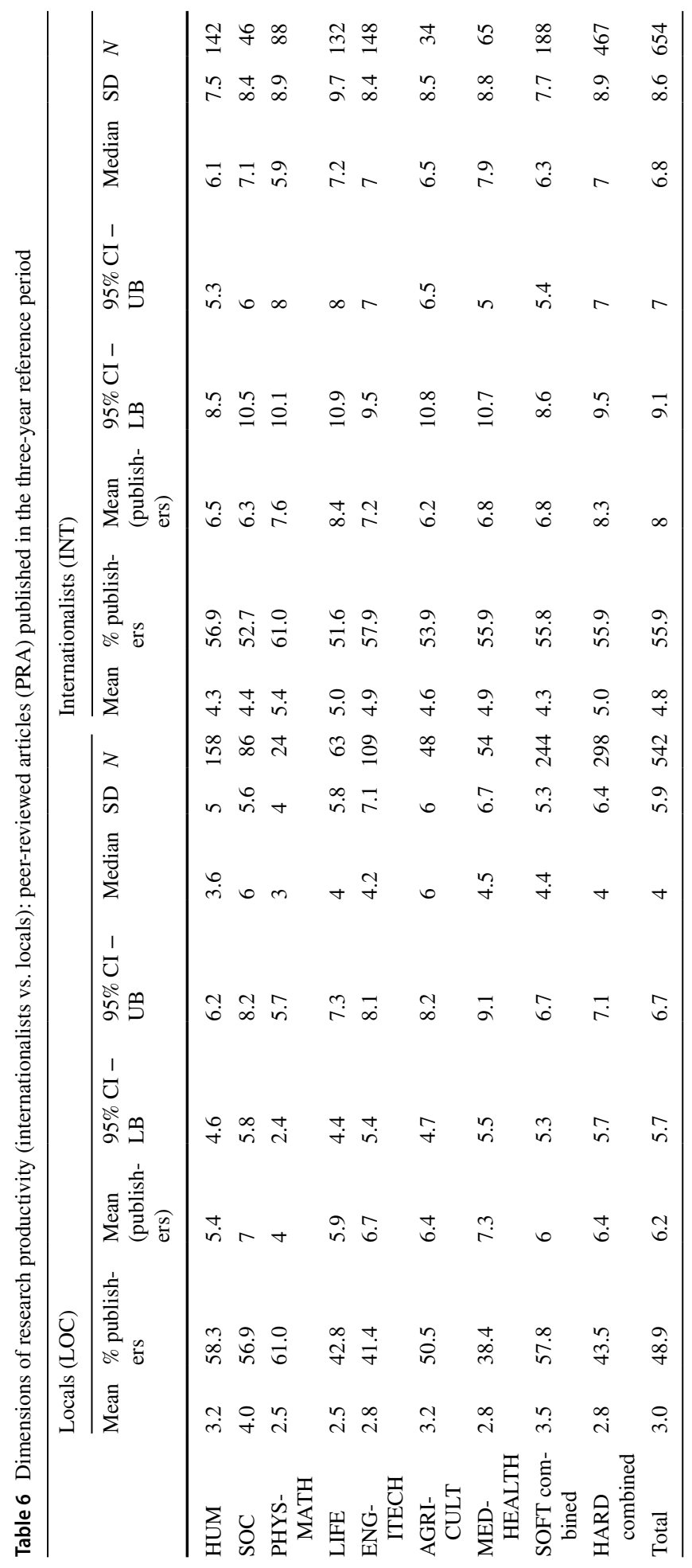




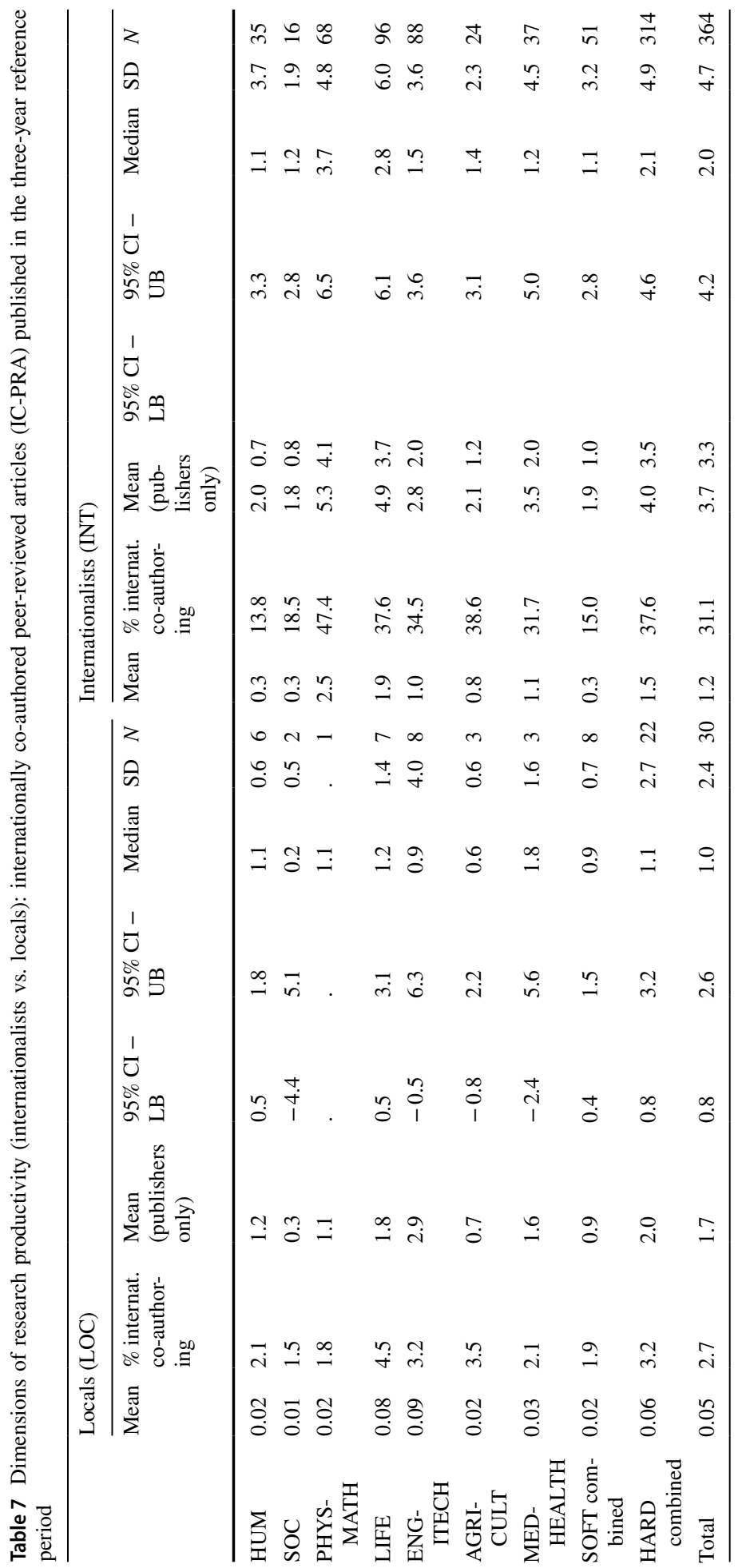




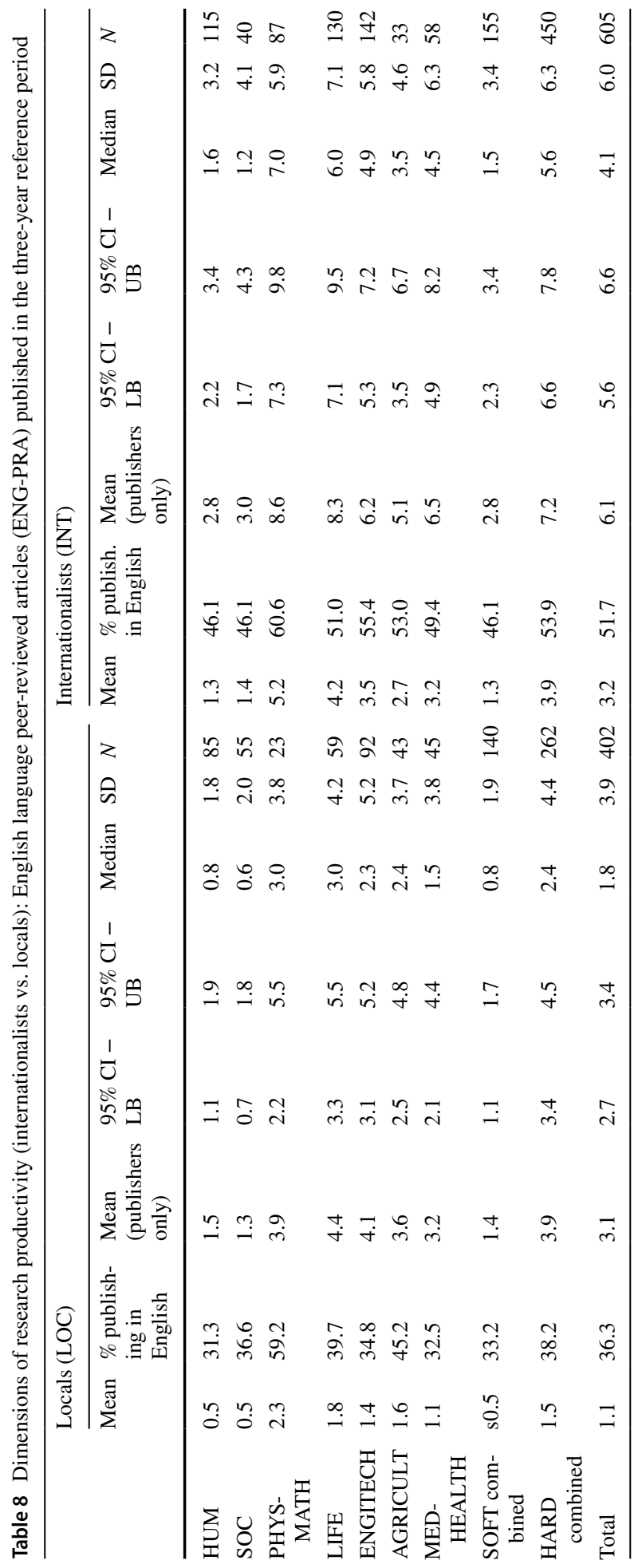


Table 9 Average research output of Polish internationalists as a share of total research output, by cluster of academic disciplines, by productivity category (IC-PRA and ENG-PRA) (in percentage)

\begin{tabular}{llll}
\hline Academic cluster & INT $(\%)$ & IC-PRA & ENG-PRA \\
\hline HUM & 48.1 & 91.1 & 71.6 \\
SOC & 36.3 & 97.4 & 62.8 \\
PHYSMATH & 78.6 & 99.8 & 89.3 \\
LIFE & 63.3 & 97.6 & 80.6 \\
ENGITECH & 49.3 & 91.1 & 69.9 \\
AGRICULT & 39.5 & 95.6 & 51.9 \\
MEDHEALTH & 45.7 & 96.6 & 72.0 \\
Total (mean) & 51.4 & 96.4 & 75.0 \\
SOFT combined & 44.4 & 92.8 & 69.0 \\
HARD combined & 54.9 & 96.6 & 75.9 \\
\hline
\end{tabular}

clusters who collaborate internationally produce almost all internationally co-authored publications - that is, no international collaboration means no internationally co-authored publications. Internationalists are also responsible for $75.0 \%$ of all Polish publications in English ENG-PRA. In PHYSMATH and LIFE, they are responsible for more than $80 \%$ of publications in English. Locals (about half of the Polish academic profession) produce only a quarter of all publications in English. In other words, non-collaboration is strongly correlated with publishing in Polish only.

Research productivity among Polish scientists is strongly correlated with international research collaboration and is consistently higher than that of Polish scientists who are not involved in international collaboration across all academic clusters and on all measures applied. International publication co-authorship is also strongly correlated with international research collaboration, ranging from 1.2 times higher than for locals (MEDHEALTH) to 5 times higher in the physical sciences and mathematics and social sciences clusters. In contrast, scientists who do not collaborate internationally report a mere $3.2 \%$ of their publications as internationally co-authored in hard science fields and no more than $1.9 \%$ in soft fields (Table 7).

The pattern is consistent for all scientists (internationalist and local) across all academic clusters, both in Poland and across European systems. Among those who do not collaborate internationally, only a marginal percentage of their publications are co-authored with colleagues from other countries. These scientists account for a substantial share of the academic profession across Europe, including $47.5 \%$ in the professions, $40.0 \%$ in engineering $31.9 \%$ in humanities and social sciences, $39.6 \%$ in life and medical sciences, and $25.3 \%$ in physical sciences and mathematics (based on a sample of 17,211 scientists from 11 systems; Kwiek 2019: 143).

\section{Individual research productivity by publication type}

Individual research productivity can also be examined by publication type beyond peerreviewed articles (see for example Sooryamoorthy 2014). For present purposes, the question was formulated as follows: "How many of the following scholarly contributions have you completed in the past three years?" (Question D4), with separate responses for scholarly books authored or co-authored, scholarly books edited or co-edited, articles published in an academic book or journal, research report/monograph written for a funded project, paper presented at a scholarly conference, and article written for a newspaper or magazine. 
The next question (D5) was formulated as follows: "What percentage of your publications in the last 3 years were: peer-reviewed" (D5/6); published in a language different from the language of instruction at your current institution (D5/1); or co-authored with colleagues located in other (foreign) countries?" (D5/3). The questionnaire distinguished explicitly between different types of publication; importantly, Polish academic scientists are used to counting different publication types for institutional reporting purposes.

The survey instrument facilitated comparison of productivity among internationalists and locals across a wide array of publication types. In every case, internationalists were found to be more productive than locals to a statistically significant extent $(p<0.001)$. Internationalists are clearly substantially more productive in terms of internationally coauthored publications: for every internationally co-authored article published by locals, internationalists publish 23.2 such articles, and for every internationally co-authored article equivalent, internationalists publish 16 such article equivalents. Internationalists are a world away from locals in terms of international co-authorship and almost three times as productive in terms of publications in English.

On average, internationalists are much more productive in terms of internationally co-authored publications. For every internationally co-authored peer-reviewed article (IC-PRA) published by locals, internationalists publish 23.2 such articles, and for every internationally co-authored peer-reviewed article equivalent (IC-PRAE), internationalists publish 16 such article equivalents. For English language peer-reviewed articles (ENGPRA), the figure is 2.9, and for article equivalents (i.e., both for articles and all types of books combined (ENG-PRAE)), it is 2.8. In this sense, internationalists are a world away from locals in terms of international co-authorship and almost three times as productive in terms of publications in English (see LOC vs. INT: the last column in Table 10). Internationalists are also about $70 \%$ more productive in terms of conference papers, and about $50 \%$ more productive in terms of peer-reviewed articles (PRA) and peer-reviewed article equivalents (PRAE). Differences in productivity by each publication type (except newspaper articles) were statistically significant. In short, Hypothesis 5 is supported.

\section{Research results: bivariate analysis}

\section{Working time distribution: internationalists vs. locals}

H6: Working time distribution hypothesis On average, internationalists work longer hours and spend more time on research, less time on teaching, and more time on administration.

This section reports the results of independent two-sample t-testing. (T-tests assess the difference in values for paired observations). In the present case, the dataset captured five dimensions of academic work: teaching, research, service, administration, and other academic activities. The focus here was on differences in mean working hours between internationalists and locals in each academic cluster, based on weekly hours during teaching and non-teaching periods of the academic year. These hours were annualized, assuming that a figure of $60 \%$ for the former and $40 \%$ for the latter would be a good approximation for the Polish system (60\% of working time annually includes teaching; $40 \%$ of working time annually does not include teaching).

Differences between the two subpopulations in various categories of working hours (by academic activity) are summarized in Table 11. The results are based on two-sided 


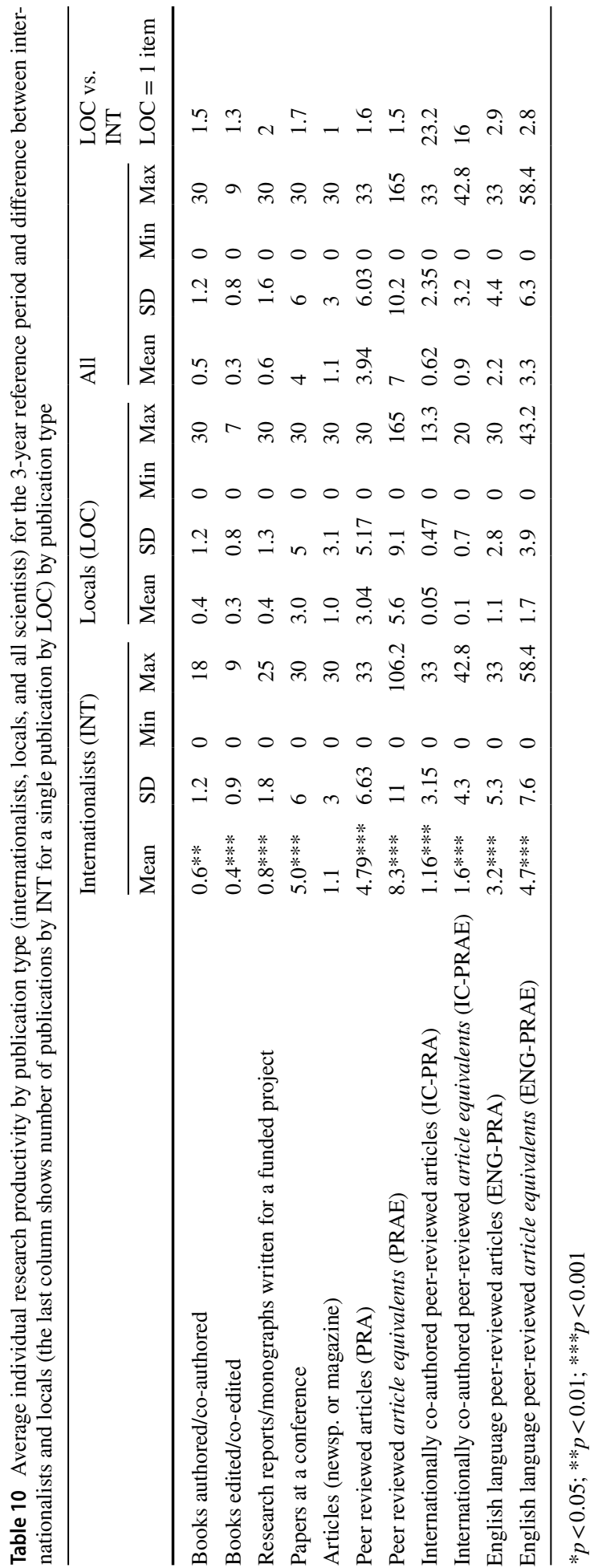


Table 11 Differential working hours by academic activity and academic cluster based on $t$-tests for equality of means for INT vs. LOC

\begin{tabular}{llllllllll}
\hline & HUM & SOC & $\begin{array}{l}\text { PHYS } \\
\text { MATH }\end{array}$ & LIFE & $\begin{array}{l}\text { ENGI } \\
\text { TECH }\end{array}$ & $\begin{array}{l}\text { AGRI } \\
\text { CULT }\end{array}$ & $\begin{array}{l}\text { MED } \\
\text { HEALTH }\end{array}$ & $\begin{array}{l}\text { Soft com- } \\
\text { bined }\end{array}$ & Hard combined \\
\hline $\begin{array}{l}\text { Teaching } \\
\text { Research }\end{array}$ & INT & INT & INT & INT & & INT & INT & INT \\
$\begin{array}{l}\text { Service } \\
\begin{array}{l}\text { Administra- } \\
\text { tion }\end{array}\end{array}$ & & & & & & & & INT & \\
$\begin{array}{l}\text { Other } \\
\text { Total }\end{array}$ & & & & INT & & INT & & INT \\
\hline
\end{tabular}

tests that assume equal differences in arithmetic means (with significance level $\alpha=0.05$ ). For each pair with a statistically significantly mean difference from zero, the larger (INT or LOC) is specified. T-tests for equality of two arithmetic means (INT vs. LOC) were performed for each of the five types of academic activity, for each of the seven academic clusters, and for soft clusters combined and hard clusters combined. (All differences were statistically significant).

The mean differential in annualized total weekly working time for internationalists and locals is $4.4 \mathrm{~h}$ (see Table 12). The picture that emerges here portrays Polish academia as traditional. On average, internationalists spend less time than locals on teaching-related activities and much more time (about $+30 \%$ ) on research, as well as more time on administrative duties. However, there are substantial cross-disciplinary differentials in total weekly working time distribution, ranging from $5.9 \mathrm{~h}$ for humanities to $11.4 \mathrm{~h}$ for social sciences.

In other words, as compared to Polish locals in social sciences, Polish internationalists in social sciences spend an average 64 additional full working days in academia per year (i.e., $11.1 \mathrm{~h}$ more per week $\times 46$ weeks, divided by $8 \mathrm{~h}$ per day). More specifically, they spend an average 9.4 additional hours per week (or 54 additional days) on research. Not surprisingly, internationalists in social sciences report the longest weekly working

Table 12 Working hour differentials by type of academic activity (for scientists from all academic clusters combined) based on t-tests for equality of means for INT vs. LOC

\begin{tabular}{|c|c|c|c|c|c|c|c|}
\hline & \multicolumn{2}{|c|}{$\begin{array}{l}\text { Mean } \\
\text { hours } \\
\text { per week } \\
\text { (annual- } \\
\text { ized) }\end{array}$} & \multirow[t]{2}{*}{$\begin{array}{l}T \text {-statistics } \\
\text { value }\end{array}$} & \multirow[t]{2}{*}{$p$ value } & \multirow[t]{2}{*}{$\begin{array}{l}\text { Significantly } \\
\text { larger mean } \\
\text { (INT or LOC) }\end{array}$} & \multirow[t]{2}{*}{$\begin{array}{l}\% \text { difference } \\
\text { (INT vs. } \\
\text { LOC) }\end{array}$} & \multirow[t]{2}{*}{$\begin{array}{l}\text { Hours per week } \\
\text { difference (INT } \\
\text { vs. LOC) }\end{array}$} \\
\hline & INT & LOC & & & & & \\
\hline Teaching & 14.8 & 16.0 & -2.875 & 0.004 & LOC & -7.6 & -1.2 \\
\hline Research & 22.3 & 17.0 & 9.201 & $<0.001$ & INT & 30.8 & 5.3 \\
\hline Service & 5.5 & 5.4 & 0.121 & 0.904 & - & 0.8 & 0.0 \\
\hline Administration & 6.7 & 5.6 & 3.749 & $<0.001$ & INT & 18.9 & 1.1 \\
\hline Other & 5.3 & 5.3 & 0.056 & 0.955 & - & 0.3 & 0.0 \\
\hline Total & 49.1 & 44.7 & 4.690 & $<0.001$ & INT & 9.8 & 4.4 \\
\hline
\end{tabular}


hours and the second longest research hours (after physical sciences and mathematics). For Polish internationalists, longer working hours seem standard (and especially more research hours). The cross-disciplinary difference is stronger in soft disciplines. In summary, Hypothesis 6 is supported.

\section{Teaching and research role orientation: internationalists vs. locals}

H7: Academic role orientation hypothesis Internationalists are more research-oriented than locals.

The existing literature suggests that research internationalization is correlated with high research orientation (Rostan et al. 2014; Shin and Cummings 2010; Teodorescu 2000). The Polish system as a whole emerges from this research as entirely traditional. The results of the $\mathrm{z}$ test for equality of fractions for the two subpopulations are based on two-sided tests with a significance level of $\alpha=0.05$. Using the Bonferroni correction, the tests were adjusted for all pairwise comparisons within a row for each innermost sub-table. $Z$ tests for the equality of fractions (INT vs. LOC) were performed for each of the four categories of teaching and research orientation. Correspondingly, as before, for each pair with a fraction difference significantly different from zero, the larger category appears in the last column (Table 13).

The stronger research role orientation among internationalists is statistically significant, as is the higher teaching role orientation among locals $(p<0.001)$. In other words, internationalists value research more than their local colleagues. A primary interest in teaching virtually excludes Polish scientists from the class of internationalists; the percentage of internationalists who are primarily interested in teaching is 1.1 percent. However, contrary to the existing evidence in relation to teaching-research competition (Fox 1992; Ramsden 1994; Stephan 2012; Stephan and Levin 1992), 18.6\% of those interested "in both, but leaning towards teaching" were internationalists. More than $80 \%$ of internationalists were research-oriented as compared to about $60 \%$ of locals. In Poland, research role orientation is a powerful indicator of the internationalist-indeed, it is almost a statistical must—while being teaching-oriented almost precludes membership of this class. On that basis, Hypothesis 7 is supported (although closer examination by academic cluster proved inconclusive).

Table 13 Results of $\mathrm{z}$ test for equality of fractions (all clusters of academic disciplines combined). (Question B2: "Regarding your own preferences, do your interests lie primarily in teaching or in research?")

\begin{tabular}{rlll}
$\begin{array}{l}\text { Internationalists } \\
\text { (INT) } \%\end{array}$ & Locals(LOC) $\%$ & $p$ value & $\begin{array}{l}\text { Significantly } \\
\text { larger frac- } \\
\text { tion }\end{array}$ \\
\hline 1.1 & 4.3 & $<0.001$ & LOC \\
18.6 & 34.9 & $<0.001$ & LOC \\
63.2 & 50.7 & $<0.001$ & INT \\
17.1 & 10.1 & $<0.001$ & INT \\
\hline
\end{tabular}




\section{Research results: multivariate analysis}

H8: Individual predictors hypothesis Individual predictors of being an internationalist are more important than organizational predictors.

\section{Model approach (I): predictors of collaboration with international research colleagues}

What are the predictors of being an internationalist? What makes some Polish scientists more likely than others to collaborate with international colleagues? The dependent variable was faculty internationalization in research ("collaborate with international colleagues in research"; D1/4; Yes/No). An analytical model for studying internationalization in research was developed on the basis of the existing literature, notably Cummings and Finkelstein (2012), Rostan et al. (2014), Finkelstein and Sethi (2014), Finkelstein et al. (2013), and Abramo et al. (2011a). From forty two selected personal and organizational characteristics, the independent variables were grouped into individual variables (36) and organizational variables (6). Individual variables were further divided into six clusters (Table 14).

All categorical variables were dichotomized using a re-coding procedure. Pearson Rho correlation tests were then conducted to identify significantly correlated predictors of the dependent variable. These predictors were entered in a logistic regression model. When multicollinearity was tested using an inverse correlation matrix, no independent variables were found to be strongly correlated with others. Additionally, principal component analysis (PCA) was performed to determine whether any variables could be assigned to homogenous groups by virtue of a high level of correlation. No significant interdependence was found between any of the variables. The model was estimated using a stepwise backward elimination based on the Wald criteria, so only significant variables were included in the model. Iterations stopped at the 32nd step. The predictive power of the model (as measured by Nagelkerke's $R^{2}$ ) was 0.502 . The results for the model are presented in Table 15.

Six individual variables and one organizational variable proved to be statistically significant. Holding full professorship emerged as a powerful determinative predictor of being an internationalist $(\operatorname{Exp}(B)=8.862)$, substantially increasing the odds of being an internationalist (other predictors being held constant). Defining one's research as primarily international in scope or orientation was also an important predictor of being an internationalist (based on the definition used here) $(\operatorname{Exp}(B)=4.692)$, as was individual's primary influence in establishing international linkages $(\operatorname{Exp}(B)=3.421)$ and being a hard scientist $(\operatorname{Exp}(B)=3.034)$. Longer weekly research hours were predictors of being an internationalist: a one-unit increase (i.e., $1 \mathrm{~h}$ ) increases the odds by about $6.2 \%$ on average (ceteris paribus) The odds were also increased significantly increased by teaching in a foreign language $(\operatorname{Exp}(B)=2.853)$ and international publication co-authoring $(\operatorname{Exp}(B)=3.034)($ Table 15).

Importantly, in the context of previous literature on international research collaboration, statistically insignificant variables included gender, spouse and family, age, as well as attachment to one's discipline and institution. In previous research in other countries, being female was generally found to be correlated with lower international collaboration (Fox et al. 2017; Abramo et al. 2013), as was having children at home (Kyvik and Teigen 1996; Ackers 2008). In Poland, only reaching the academic career pinnacle (full professorship) increases the odds of collaborating internationally in research; neither doctoral degree nor 
Table 14 Internationalization in research: variables in the model (survey question numbers in parentheses)

Personal/demographics

Gender (F1)

Marital status (married or not) (F3)

Spouse employed (F4)

Spouse an academic (F5)

Spouse education level (F8-3)

Children under 18 at home (F6)

Age (F2)

Academic experience-years since first employment (A4)

PhD or lower degree (A1)

Habilitation degree (A1)

Full professorship (A1)

My academic discipline/field is important (B4)

My institution is important (B4)

Satisfaction with current job (B6)

Internationalization and collaboration

Emphasize international perspective or content in their courses $(\mathrm{C} 4 / 5,1$ and 2)

Most international students are currently international (C4/10, 1 and 2)

Teaching any courses abroad (C5/2, Yes/No)

Teaching any courses in a foreign language (C5/2, Yes/No)

Research primarily international in scope or orientation (D2/5, 1 and 2)

Employ primarily mother tongue in research $(\mathrm{F} 12 / 1$, Yes/No)

Publishing in a foreign country (D5/4, Yes/No, $>0)$

Publishing in a foreign language (D5/1, Yes/No, $>0$ )

Publishing works co-authored with colleagues located in other countries (D5/1, Yes/No, >0)

Spent at least two years in other countries since the award of their first degree (F13/3, Yes/No)

$\mathrm{PhD}$ earned in a foreign country (A1/2/2).

Socialization to academia

Intensive faculty guidance (A3)

Research projects with faculty (A3)

Academic behaviors

Annualized mean weekly research hours (B1)

Annualized mean weekly teaching hours (B1)

Annualized mean weekly admin. hours (B1)

Academic attitudes and role orientation

Research-oriented (only answer 4) (B2)

Scholarship is original research (B5)

Basic/theoretical research (D2)

Research productivity

Peer-reviewed articles (PRA) (D4/2 and D4/3)

Organizational variables

Organizational environment

Strong performance orientation (E4)

Institutional type (A9)

Research considered in personnel decisions (E6)

Availability of research funds (B3) 
Table 14 (continued)

Supportive attitude of administration (E4)

Who has primary influence in establishing international linkages (individual/faculty) (E1)

habilitation degree enter the equation. In other words, international research collaboration is strongly correlated with high research achievement (leading to the full professorship title, as research is the only criterion used in the Polish system; the full professorship title as a binary variable is correlated with research productivity understood as the number of peerreviewed articles published in the reference period). Age is not a statistically significant predictor; full professors rather than merely older scientists tend to be more often engaged in international collaboration (for a quantitative and qualitative generational approach, see Kwiek 2017). In summary, Hypothesis 8 is supported.

\section{Model approach (II): How internationalization influences productivity}

H9: Productivity type hypothesis Dimensions of internationalization differ in their impact on different productivity measures.

Finally, a modeling approach was also used to investigate how general variables and variables related to internationalization (in teaching and research) influence various aspects of productivity. As measures of productivity, dependent variables included PRA, PRAE, ICPRAE, and ENG-PRAE. Productivity-related independent variables included gender, age, institutional type (reference: academy), academic degree (reference: $\mathrm{PhD}$ ), academic field (reference: HUM). Finally, internationalization-related independent variables included responses to statements about international content in courses, collaboration with international colleagues in research, having international students, teaching any courses abroad or in a foreign language, research being primarily international in scope or orientation, employing in research primarily mother tongue, as well as publishing in a foreign country, in a foreign language, publishing works co-authored with colleagues located in other countries, spending at least 2 years in other countries since the award of first degree, and earning $\mathrm{PhD}$ in a foreign country.

Table 16 details the results of regression analysis, with models for each of the four productivity types (PRA, IC-PRA, ENG-PRA and PRAE) (all types: peer-reviewed). For each productivity type, there are three separate models: all scientists (ALL), internationalists (INT), and locals (LOC). In total, then, twelve models (1 through 12 in Table 16) were estimated; beta coefficients and significance of parameters are shown for each.

In the first regression model of productivity (dependent variable: PRA) for all scientists (Model 1), the general independent variables significantly associated with productivity were age, habilitation degree, full professorship title, and life sciences; the significant internationalization-related independent variables were publishing in a foreign country, publishing in a foreign language, and international co-authorship. The model explains $41 \%$ of the variance $\left(R^{2}=0.409\right)$. In summary, older scientists are likely to produce fewer papers, and all internationalization-related variables increase productivity.

In the second regression model of productivity (PRA) for internationalists (Model 2 ), the general independent variables significantly associated with productivity were age, habilitation degree, full professorship title; and two internationalization-related 


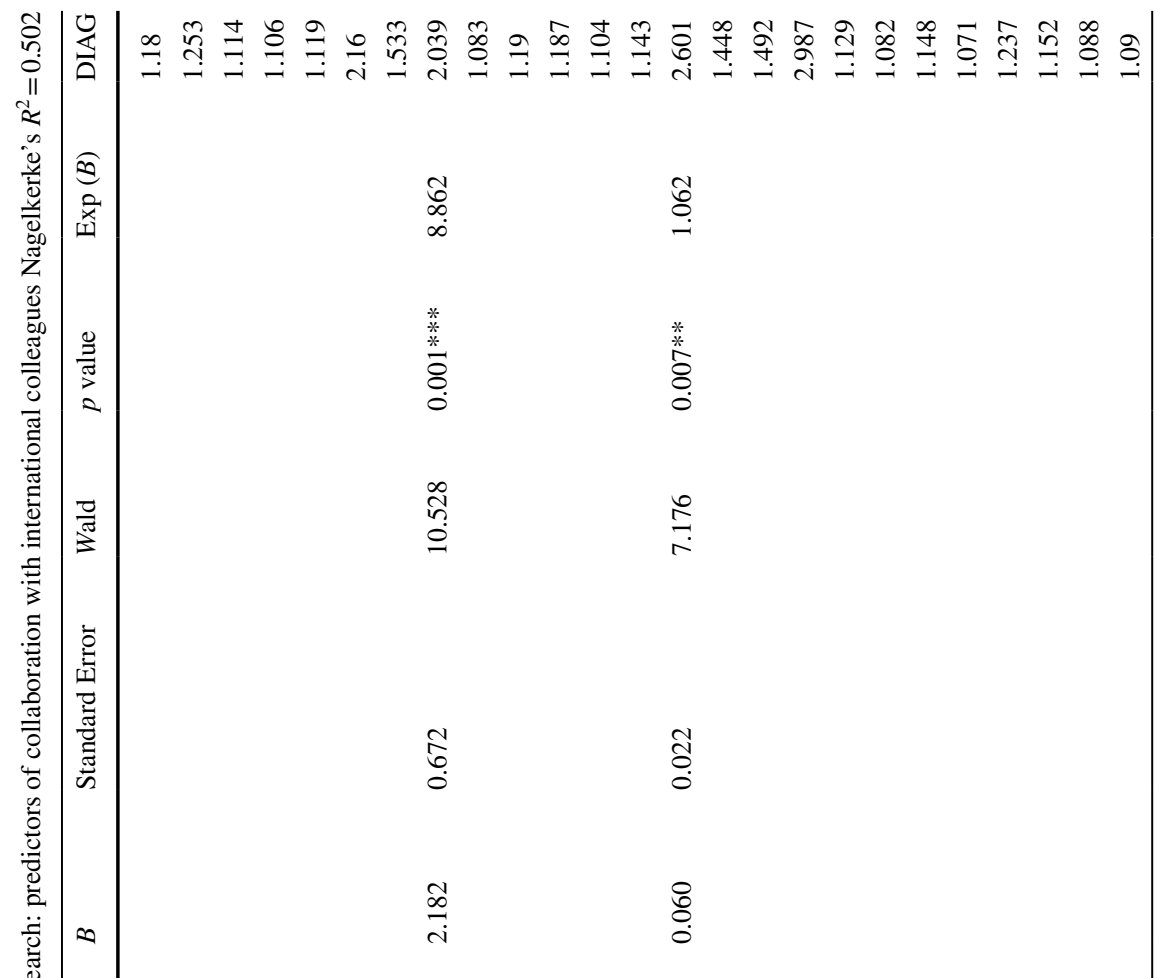

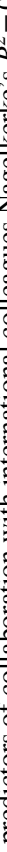




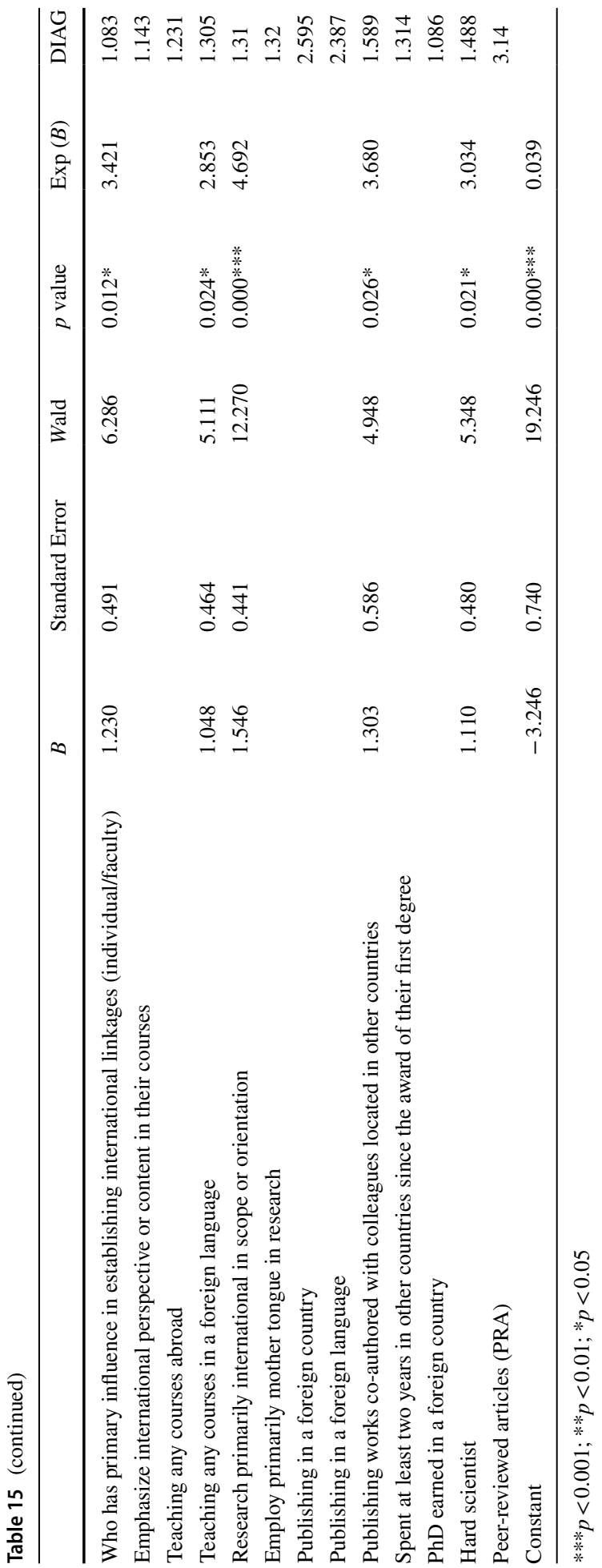




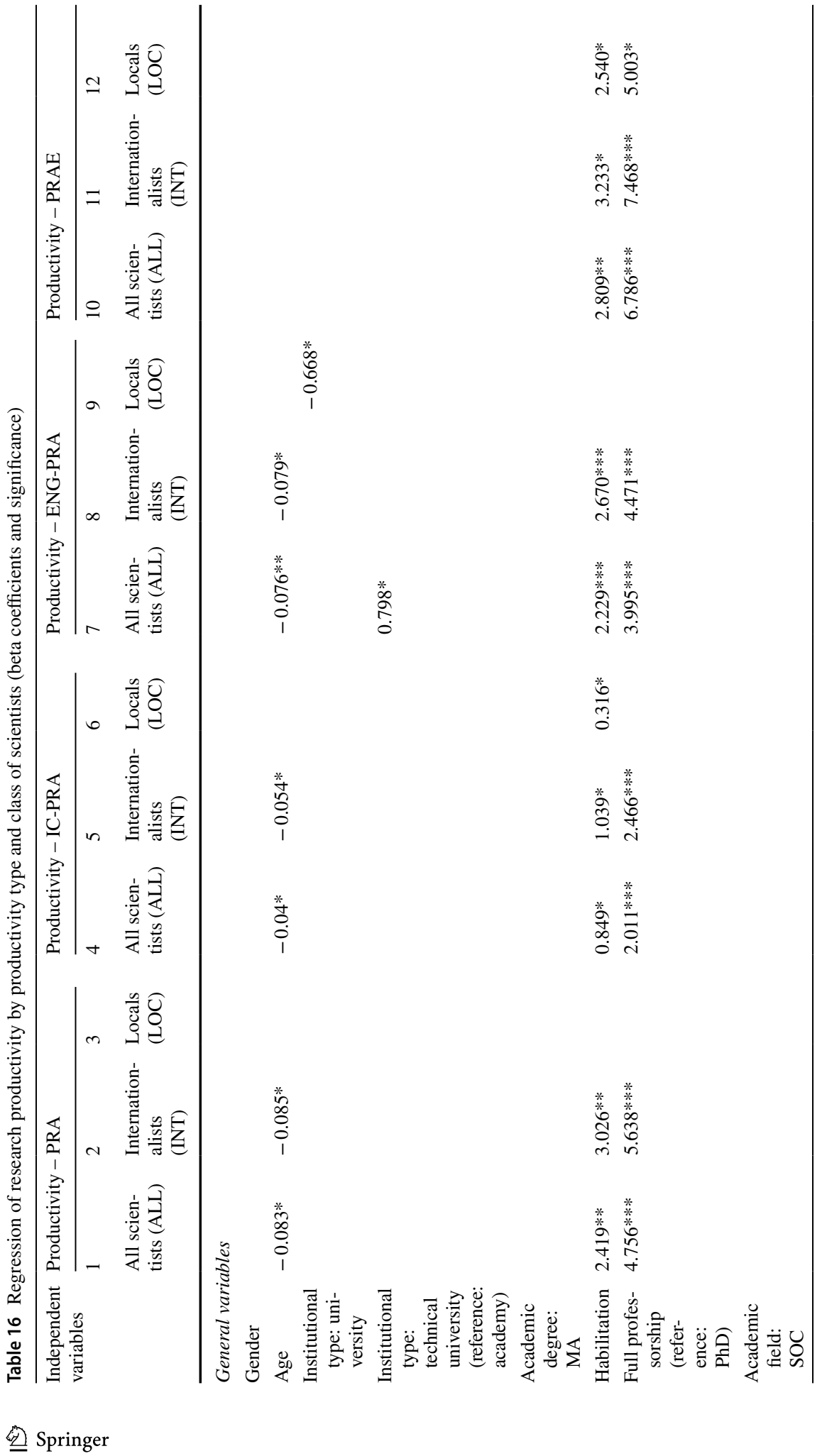




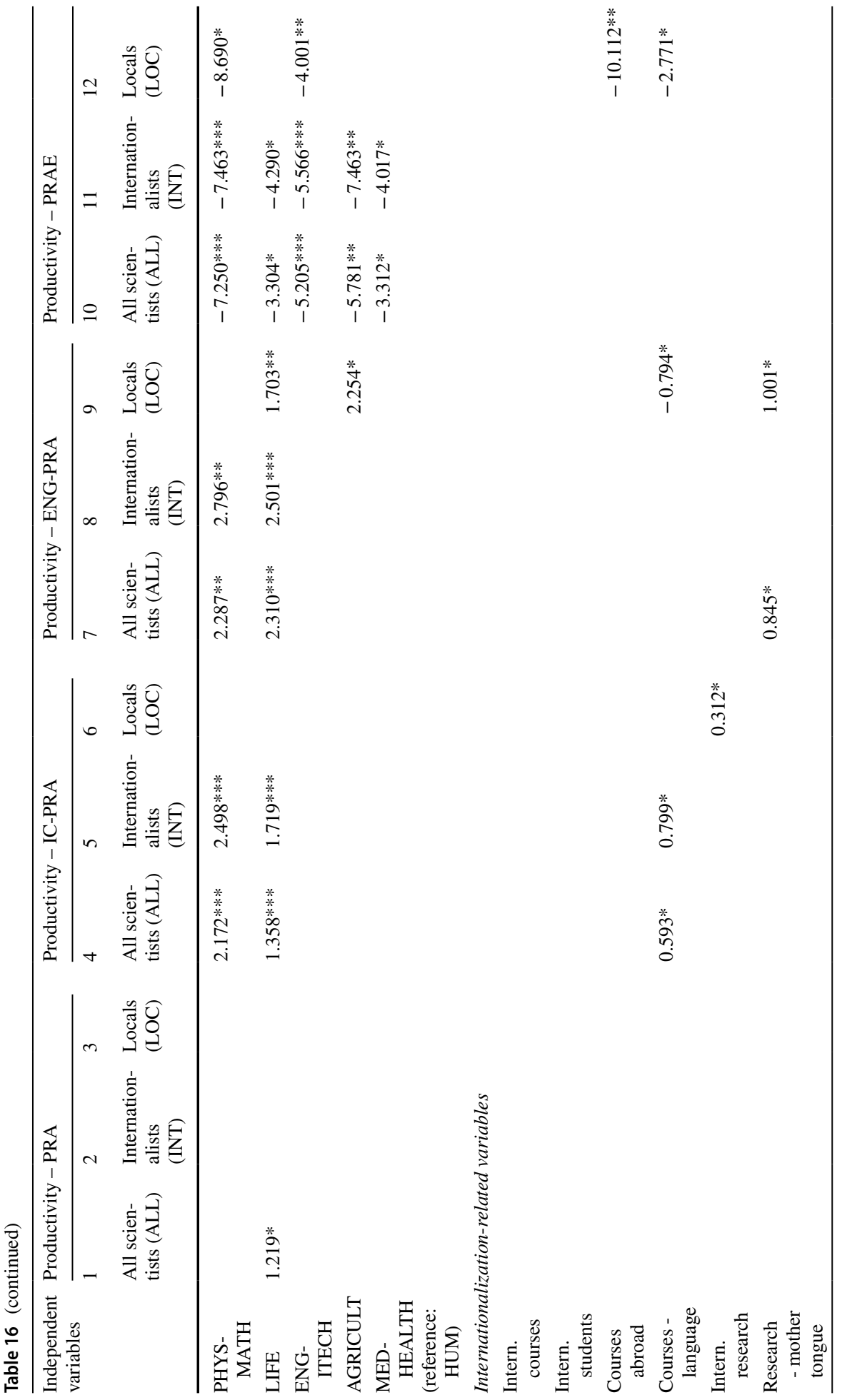




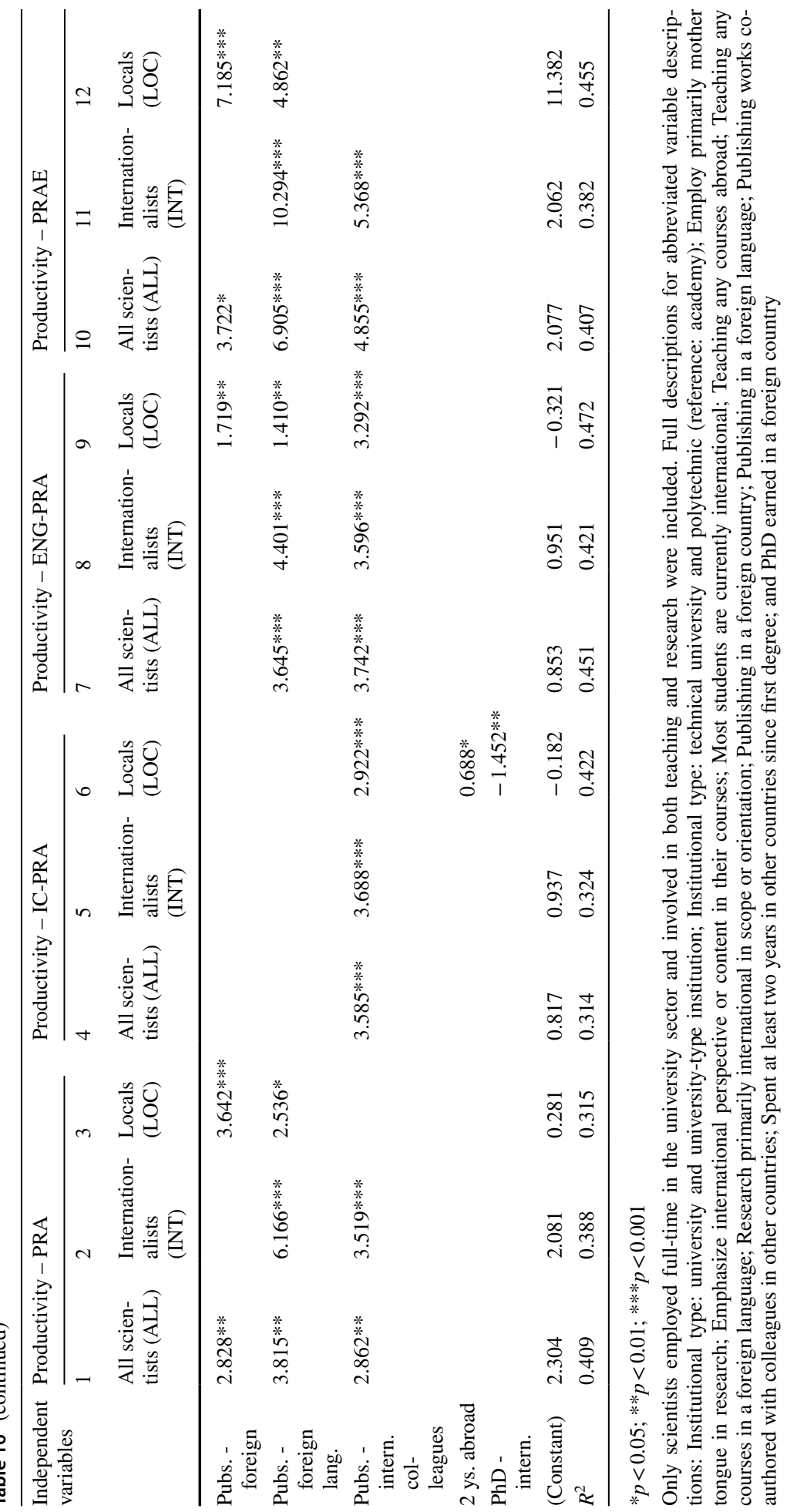


independent variables: publishing in a foreign language, and international co-authorship. As in Model 1, there was a powerful negative correlation between age and productivity. The model explains almost $40 \%$ of the variance $\left(R^{2}=0.388\right)$. Finally, in the regression model of productivity (PRA) for locals (Model 3), only two independent variables (both internationalization-related) were significant: publishing in a foreign country and publishing in a foreign language $\left(R^{2}=0.315\right)$. In models 4 through 6 , IC-PRA was the dependent variable; in Models 7 through 9, the dependent variable was ENG-PRA; and in Models 10 through 12, PRAE was the dependent variable - again with separate models for all scientists, internationalists, and locals.

The analyses reveal some interesting generalizations and several exceptions. Interestingly, gender does not enter the equation in any model for any productivity-related dependent variable. Age as an independent variable is not correlated with productivity for locals in any of the four clusters of regression models, nor for the three types of scientist in the case of article equivalents as dependent variable (Models 10-12). This can be explained by the fact that locals are more attached to traditional (and generally less competitive) publishing outlets of books and edited books. Habilitation degree and professorship are significantly correlated with all scientists and internationalists (rather than with locals), perhaps explaining why international collaboration is strongly correlated with productivity as measured through all its dependent variables (PRA, IC-PRA, ENG-PRA, and PRAE). For locals, the correlation holds only for article equivalents, which means that locals move up the ladder of scientific degrees and titles through traditional outlets (books and edited books) rather than articles. International content or orientation in teaching and teaching international students as (teaching-related) internationalization independent variables are not correlated with productivity. Teaching in a foreign language is negatively correlated with productivity in ENG-PRA and PRAE models. This confirms the traditional teaching/research trade off, or competition rather than mutuality (Fox 1992) in Polish academia, or at least supplies the missing link between internationally-oriented teaching and research productivity, in line with previous findings (Kwiek 2015b). Interestingly, and somehow counter-intuitively, among internationalization-related independent variables, neither long-term stay abroad nor foreign $\mathrm{PhD}$ are correlated with productivity, confirming previous findings about mobility, collaboration, and productivity (Ackers 2008; Kyvik and Larsen 1997; Rostan et al. 2014; and Cummings and Finkelstein 2012). Ackers (2008: 430-432) suggests a clear distinction to be made between long-term mobility and short stays abroad, with each bringing different added value to research and researchers. Earning PhD abroad as the only academic socialization variable used in the model decreases the odds of international research collaboration in a sample of scientists from 11 European systems (Kwiek 2018a: 19). The specific cases would probably be long-term stays in the USA as the global science hub and $\mathrm{PhD}$ earned there rather than anywhere else, more prestigious institutions leading to more "reputational capital" (Ackers 2008: 421); however, our survey instrument did not allow to distinguish between the countries visited. Our results are in line with findings about Norwegian scientists: long-term professional stays abroad, if not followed up by keeping in touch with foreign colleagues, lead to "virtually no differences in productivity" (Kyvik and Larsen 1997: 254). Also in a study of scientists from 19 countries, $\mathrm{PhD}$ earned abroad was not a predictor of international research collaboration (Rostan et al. 2014: 128-129); and in the case of the USA, earning $\mathrm{PhD}$ outside of the country was not a predictor of international research collaboration either (Cummings and Finkelstein 2012: 97-101). Only in the 
case of the IC-PRA model for locals, productivity increases with long-term stay abroad (on average by 0.7 internationally co-authored peer-reviewed article in the reference period of 3 years) and decreases with foreign $\mathrm{PhD}$ (on average by 1.5). Hypothesis 9 is therefore supported.

\section{Summary, discussion, and conclusions}

The present findings reveal that some scientists are clearly more internationalized than others, and this distinction permeates the Polish academic science community. Internationalization divides the academic community in terms of prestige, recognition, and access to competitive research funding. Research internationalization is a powerful stratifying force, causing both vertical between-institution differentiation and horizontal within-institution segmentation across faculties. In the Polish science system, highly internationalized institutions, faculties, research groups, and individuals are increasingly separate from their local counterparts.

In the present case, nine hypotheses were tested, drawing on a large sample $(N=3704$ returned questionnaires) of Polish academic scientists across all disciplines. Using survey-based rather than bibliometric data, the research explored a wider than usual range of international collaboration factors, including gender, age, academic seniority, academic field, domestic collaboration, productivity, working time distribution, and academic role orientation. Using a multivariate approach, individual and organizational predictors of internationalism and the impact of internationalization on productivity were also measured.

In this research, internationalists emerge as a clearly defined subgroup of Polish scientists (51.4\%) - in effect, a different academic species as compared to locals. Internationalists are predominantly male (as in Rostan et al. 2014; Vabø et al. 2014), and this gender differential has powerful policy implications (as voiced by Ackers in her study of internationalization as a form of discrimination (2008)). If an individual's success in a globally stratified academia depends on research rather than on teaching, service, or administration, and if research success and productivity are driven by international collaboration (Abramo et al. et al. 2011a), then female scientists are increasingly likely to lose out in terms of funding and prestige. This is especially the case in resource-poor systems where competition is tougher, and the process of internationalization accumulative disadvantage means that the poor get poorer while the rich get richer. International research stratification is more harmful to female scientists because international collaboration is strongly correlated with higher publishing rates (as well as higher citation rates, which are not explored here). In the Polish context, 55\% of female scientists are locals, as compared to $44 \%$ of their male colleagues. Our findings support conclusions drawn by Abramo et al. (2013) about Italian scientists: male scientists exhibit higher collaboration rates in international collaboration. Our findings do not, however, support conclusions from Aksnes et al. (2019), who found that gender is not an important determinant of international research collaboration. Consequently, in the Polish case, women's progression on the academic ladder is likely to be more difficult and more protracted, with less access to increasingly competitive individual research funding.

Internationalists are also older, with longer academic experience and higher academic degrees and occupying higher academic positions, which aligns with most previous research (as in Jung, Kooij and Teichler 2014; Rostan 2015; Rostan et al. 2014). In 
resource-poor systems like Poland, internationalists are a majority only among those over 50, with more than 20 years of academic experience and a habilitation degree and associate professorship at minimum. The emerging pattern is clear and statistically significant; only a handful of full professors (74.6\% of whom are internationalists) achieve the high levels of research internationalization seen in resource-rich systems. That said, the share of young internationalists is certainly increasing, with highly competitive new research programs funded by the National Research Council (or NCN, founded in 2011) dedicated predominantly to young academics (Bieliński and Tomczyńska 2018).

The present findings also align with previous evidence (Kyvik and Larsen 1997; Piro et al. (2013) that internationalization is highly discipline-sensitive. Up to $80 \%$ of academics in the physical sciences and mathematics cluster are internationalists as against only $36.3 \%$ in the social sciences, as are more than $90 \%$ of full professors in the physical sciences and mathematics as compared to only $50 \%$ in the social sciences. In the humanities and social sciences, $63.3 \%$ of locals do not collaborate domestically either, which means that the "lonely scholar" model prevails, consistently with findings in Lewis (2013).

Interestingly, international collaboration does not occur at the expense of domestic collaboration; in fact, although this dimension has rarely been studied, internationalists also collaborate extensively at domestic level (Sooryamoorthy 2014; Jeong et al. 2011). Only $20.5 \%$ of internationalists do not collaborate domestically, for unknown reasons that may include lack of time, lack of funding, or limited opportunities to co-publish internationally. At the other extreme, only $50 \%$ of locals collaborate domestically-in other words, half of those who do not collaborate internationally also fail to collaborate domestically, again with significant field differentiation.

In terms of research productivity, internationalists co-author internationally six times more often than locals, among whom international co-authorship is marginal $(2.1 \%$ as compared to $13.8 \%$ for internationalists), following the patterns known from literature (Kyvik and Larsen 1997; Abramo et al. 2011a). Across all academic clusters, internationalists consistently produce more than $90 \%$ of internationally co-authored publications; in the fields of physics and mathematics, social sciences and life sciences, the figure is $97-99.9 \%$. In these clusters, no international collaboration means no internationally co-authored publications.

Scientists who do not collaborate internationally report very low shares of internationally co-authored publications (3.2\% in hard fields and $1.9 \%$ in soft fields). The fact that only internationalists are generally involved in large-scale international co-authorship has policy implications, as only a negligible fraction of publications produced by Polish locals are internationally co-authored and depend almost entirely on collaborative activities with international colleagues. Given the current policy goal of increasing Polish visibility in global science, it may be counter-productive to support research locals through additional funding (competitive or otherwise), as this would deprive internationalists of already limited research funds.

The survey instrument facilitated comparison of productivity among internationalists and locals across a wide array of publication types. In every case, internationalists were found to be more productive than locals to a statistically significant extent $(p<0.001)$. Internationalists are clearly much more productive in terms of internationally co-authored publications: for every internationally co-authored article published by locals, internationalists publish 23.2 such articles, and for every internationally co-authored article equivalent, internationalists publish 16 such article equivalents. Internationalists are a world apart from locals in terms of international co-authorship and almost three times as productive in terms of publications in English. 
In terms of work-time distribution and academic role orientation, Polish academia is fairly traditional. Internationalists tend to spend less time than locals do on teaching-related activities, more time on research, and more time on administrative duties, with cross-disciplinary differentials in total weekly work-time distribution (as suggested by Fox 1992; Ramsden 1994; Stephan 2012). In terms of work patterns, the largest gap was observed in the social sciences, where internationalists spend an average of 64 additional days each year on academic activities. Internationalists also exhibit higher research role orientation; in contrast, locals are more teaching-oriented. A primary interest in teaching virtually excludes Polish scientists from the class of internationalists, of whom only $1.1 \%$ are primarily teaching-oriented.

From a European comparative perspective (Kwiek 2018a), the share of internationalists in Poland is low, and the share of young internationalists is very low. However, Poland is not an outlier and belongs to a cluster of internationalization laggards, together with Germany, Portugal, and Italy-a cluster that can be contrasted with a cluster of internationalization leaders (comprising the Netherlands, Ireland, Austria, and Switzerland). The share of internationalists in the latter cluster reaches $75-80 \%$, and in the former cluster it is in the range of $50-60 \%$. However, for the youngest generation, the difference between the countries with $80 \%$ of young scientists collaborating internationally (as in the Netherlands, Ireland, and the United Kingdom) and those with $40 \%$ collaborating internationally (as in Germany, Poland, and Portugal) may be a strong barrier to intra-European collaboration in the future. The reasons for international non-collaboration certainly differ from country to country. While severe research underfunding would figure prominently among major factors in Poland, good research funding and the large size of the science system (the second largest in Europe after the United Kingdom) would be a major factor in Germany.

Multivariate analyses identified some new predictors of international research collaboration. Variables that substantially increase the odds of being a research internationalist include full professorship, working in a hard academic discipline, working long research hours, international co-authorship, and individual rather than institutional international linkages. Unsurprisingly in the Polish context, independent variables related to teaching were negatively correlated with international productivity. There was also statistical evidence of the traditional teaching/research trade-off in Polish academia. Among internationalization-related independent variables, long-term stays abroad and foreign $\mathrm{PhD}$ awards were not generally positively correlated with productivity, confirming previous findings about mobility, collaboration, and productivity (Ackers 2008; Kyvik and Larsen 1997; Rostan et al. 2014).

Our next steps include a comparison of the internationalist/local contrast as it emerges from survey data, with a parallel contrast emergent from publication and citation data. The usefulness of the present definition of internationalists as scientists who collaborate internationally in research will be compared with the usefulness of a bibliometric definition of internationalists as scientists with a certain proportion of articles published through international collaboration in their individual publication portfolios (within a given timeframe). While a limitation of research in survey-based cross-national comparative studies is cost (coordination, funding for national teams, time invested in data collection and cleaning in specific national contexts etc.), in bibliometric-based research, these costs can be substantially reduced once specific datasets have been built. For future Polish case studies, we will use "The Polish Science Observatory" dataset. This dataset has full administrative, biographical, and bibliometric data concerning 100,000 scientists and their 400,000 Scopusindexed articles published in the decade 2009-2018. And for cross-national comparative research, we will use our global bibliometric dataset of 27.6 million articles published in 
the OECD area by authors from 1874 institutions (with at least 3000 articles) in the same period, with a number of gender-defining algorithms, software, and global datasets. Both datasets are maintained by the Center for Public Policy Studies and will be periodically updated.

In sum, the present findings confirm the stratifying power of international collaboration in a science system in transition from severe underfunding and a strong national focus to more affluent but highly competitive funding and a strong international focus. Internationalists and locals are different in terms of how they work, how they think about their roles, and how they publish and collaborate. They also face different barriers in securing academic promotion and research funding. The balance of research internationalists and locals is currently about 50-50, but this is bound to change in an emergent system that is focused increasingly on research internationalization.

Acknowledgements The author gratefully acknowledges the support of the National Ministry of Science and Higher Education through its Dialogue grant 0022/DLG/2019/10 (RESEARCH UNIVERSITIES). The support of Dr. Wojciech Roszka is also gratefully acknowledged. Finally, my exceptional gratitude goes to the two anonymous reviewers for their patience and highly constructive, detailed criticism of the original manuscript.

Open Access This article is licensed under a Creative Commons Attribution 4.0 International License, which permits use, sharing, adaptation, distribution and reproduction in any medium or format, as long as you give appropriate credit to the original author(s) and the source, provide a link to the Creative Commons licence, and indicate if changes were made. The images or other third party material in this article are included in the article's Creative Commons licence, unless indicated otherwise in a credit line to the material. If material is not included in the article's Creative Commons licence and your intended use is not permitted by statutory regulation or exceeds the permitted use, you will need to obtain permission directly from the copyright holder. To view a copy of this licence, visit http://creativecommons.org/licenses/by/4.0/.

\section{References}

Abramo, G., D’Angelo, C. A., \& Di Costa, F. (2019). A gender analysis of top scientists' collaboration behavior: evidence from Italy. Scientometrics. Published online: 30 May 2019.

Abramo, G., D’Angelo, C. A., \& Murgia, G. (2013). Gender differences in research collaboration. Journal of Informetrics, 7, 811-822.

Abramo, G., D’Angelo, C. A., \& Murgia, G. (2016). The combined effect of age and seniority on research performance of full professors. Science and Public Policy, 43(3), 301-319.

Abramo, G., D’Angelo, C. A., \& Solazzi, M. (2011a). The relationship between scientists' research performance and the degree of internationalization of their research. Scientometrics, 86, 629-643.

Abramo, G., D’Angelo, C. A., \& Solazzi, M. (2011b). Are researchers that collaborate more at the international level top performers? An investigation on the Italian university system. Journal of Informetrics, 5, 204-213.

Ackers, L. (2008). Internationalization, mobility and metrics: A new form of indirect discrimination? Minerva, 46, 411-435.

Aksnes, D. W., Piro, F. N., \& Rørstad, K. (2019). Gender gaps in international research collaboration: a bibliometric approach. Scientometrics. Published online: 13 June 2019.

Antonowicz, D. (2016). Digital players in an analogue world: Higher education in Poland in the post-massification era. In B. Jongbloed \& H. Vossensteyn (Eds.), Access and expansion post-massification. Opportunities and barriers to further growth in higher education participation (pp. 63-81). London: Routledge.

Antonowicz, D., Kwiek, M., \& Westerheijden, D. F. (2017). The government response to the private sector expansion in Poland. In H. de Boer, J. File, J. Huisman, M. Seeber, M. Vukasovic, \& D. F. Westerheijden (Eds.), Policy analysis of structural reforms in higher education (pp. 119-138). Dordrecht: Springer.

Beaver, D. D. (2001). Reflections on scientific collaboration (and its study): Past, present, and future. Scientometrics, 52(3), 365-377. 
Bentley, P. J. (2015). Cross-country differences in publishing productivity of academics in research universities. Scientometrics, 102(1), 865-883.

Bieliński, J. \& Tomczyńska, A. (2018). The ethos of science in contemporary Poland. Minerva. On-line first: https://link.springer.com/article/10.1007/s11024-018-9365-1.

Bonaccorsi, A., \& Daraio, C. (2003). Age effects in scientific productivity. The case of the Italian National Research Council (CNR). Scientometrics., 58(1), 49-90.

Bozeman, B., \& Boardman, C. (2014). Research collaboration and team science. A state-of-the-art review and agenda. Cham: Springer.

Bryman, A. (2012). Social research methods (4th ed.). Oxford: Oxford University Press.

Carvalho, T. (2017). The study of the academic profession-Contributions from and to the sociology of professions. In J. Huisman \& M. Tight (Eds.), Theory and method in higher education research (1st ed., pp. 59-76). Bingley: Emerald Group Publishing Limited.

Cohen, L., Manion, L., \& Morrison, K. (2011). Research methods in education. New York: Routledge.

Cole, J. R., \& Cole, S. (1973). Social stratification in science. Chicago: University of Chicago Press.

Costas, R., van Leeuwen, T. N., \& Bordons, M. (2010). A bibliometric classificatory approach for the study and assessment of research performance at the individual level: The effects of age on productivity and impact. Journal of the American Society for Information Science and Technology, 61(8), 1564-1581.

Cummings, W. K., \& Finkelstein, M. J. (2012). Scholars in the changing American Academy. Dordrecht: Springer.

Cummings, J. N., \& Kiesler, S. (2007). Coordination costs and project outcomes in multi-university collaborations. Research Policy, 36, 1620-1634.

Dakowska, D. (2015). Between competition imperative and Europeanisaton: The case of higher education reform in Poland. Higher Education, 69(1), 129-141.

Finkelstein, M., \& Sethi, W. (2014). Patterns of Faculty Internationalization: A Predictive Model. In F. Huang, M. Finkelstein, \& M. Rostan (Eds.), The internationalization of the academy. Changes, realities and prospects (pp. 237-258). Dordrecht: Springer.

Finkelstein, M. J., Walker, E., \& Chen, R. (2013). The American faculty in an age of globalization: Predictors of internationalization of research content and professional networks. Higher Education, 66, 325-340.

Fox, M. F. (1992). Research, teaching, and publication productivity. Mutuality versus competition in academia. Sociology of Education, 65(4), 293-305.

Fox, M. F., Realff, M. L., Rueda, D. R., \& Morn, J. (2017). International research collaboration among women engineers: Frequency and perceived barriers, by regions. Journal of Technology Transfer, 42(6), 1292-1306.

Gazni, A., Sugimoto, C. R., \& Didegah, F. (2012). Mapping world scientific collaboration: Authors, institutions, and countries. Journal of the American Society for Information Science and Technology, 63(2), 323-335.

Georghiou, L. (1998). Global cooperation in research. Research Policy, 27, 611-628.

Glenn, N. D. (2005). Cohort analysis. Thousand Oaks: Sage.

Gorelova, O., \& Lovakov, A. (2016). Academic inbreeding and research productivity of Russian Faculty Members. Working Papers. WP BRP 32/EDU/2016.

Gouldner, A. (1957). Cosmopolitans and locals: Toward an analysis of latent social rules. Administrative Science Quarterly, 2, 281-306.

GUS. (2011). Higher education institutions and their finances in 2010. Warsaw: GUS (Central Statistical Office).

Hibberts, M. R., Johnson, B., \& Hudson, K. (2012). Common survey sampling techniques. In L. Gideon (Ed.), Handbook of survey methodology for the social sciences (pp. 53-74). Dordrecht: Springer.

Hoekman, J., Frenken, K., \& Tijssen, R. J. W. (2010). Research collaboration at a distance : Changing spatial patterns of scientific collaboration within Europe. Research Policy, 39, 662-673.

Jeong, S., Choi, J. Y., \& Kim, J.-Y. (2011). The determinants of research collaboration modes: Exploring the effects of research and researcher characteristics on co-authorship. Scientometrics, 89, 967-983.

Jeong, S., Choi, J. Y., \& Kim, J.-Y. (2014). On the drivers of international collaboration: The impact of informal communication, motivation, and research resources. Science and Public Policy., 41(4), $520-531$.

Jung, J. (2014). Research productivity by career stage among Korean Academics. Tertiary Education and Management, 20(2), 85-105.

Jung, J., Kooij, R., \& Teichler, U. (2014). Internationalization and the new generation of academics. In F. Huang, M. Finkelstein, \& M. Rostan (Eds.), The internationalization of the academy. Changes, realities and prospects (pp. 207-236). Dordrecht: Springer.

Katz, J. S., \& Martin, B. R. (1997). What is research collaboration? Research Policy, 26, 1-18. 
Knorr Cetina, K. (1999). Epistemic cultures. How the sciences make knowledge. Cambridge, MA: Harvard University Press.

Kulczycki, E. (2019). Wzory publikacyjne polskich naukowców w latach 2013-2016. Nauki humanistyczne $i$ nauki społeczne. https://doi.org/10.6084/m9.figshare.7797527.

Kulczycki, E., Korzeń, M., \& Korytkowski, P. (2017). Toward an excellence-based research funding system: Evidence from Poland. Journal of Informetrics, 11(1), 282-298.

Kwiek, M. (2012). Changing higher education policies: From the deinstitutionalization to the reinstitutionalization of the research mission in Polish universities. Science and Public Policy, 35(5), 641-654.

Kwiek, M. (2015a). The internationalization of research in Europe. A quantitative study of 11 national systems from a micro-level perspective. Journal of Studies in International Education, 19(2), $341-359$.

Kwiek, M. (2015b). Academic generations and academic work: Patterns of attitudes, behaviors and research productivity of Polish academics after 1989. Studies in Higher Education, 40(8), 1354-1376.

Kwiek, M. (2016). The European research elite: A cross-national study of highly productive academics across 11 European systems. Higher Education, 71(3), 379-397.

Kwiek, M. (2017). A generational divide in the Polish academic profession. A mixed quantitative and qualitative approach. European Educational Research Journal, 17, 1-26.

Kwiek, M. (2018a). International research collaboration and international research orientation: Comparative findings about European Academics. Journal of Studies in International Education., 22(2), 136-160.

Kwiek, M. (2018b). High research productivity in vertically undifferentiated higher education systems: Who are the top performers? Scientometrics, 115(1), 415-462.

Kwiek, M. (2019). Changing European academics: A comparative study of social stratification, work patterns and research productivity. London and New York: Routledge.

Kwiek, M. (2020). What large-scale publication and citation data tell us about international research collaboration in Europe: Changing national patterns in global science. Studies in Higher Education. https ://doi.org/10.1080/03075079.2020.1749254.

Kwiek, M., \& Roszka, W. (2020). Gender disparities in international research collaboration: A large-scale bibliometric study of 25,000 university professors. https://arxiv.org/abs/2003.00537.

Kwiek, M., \& Szadkowski, K. (2018). Higher education systems and institutions: Poland. In P. N. Texteira \& J. C. Shin (Eds.), International encyclopedia of higher education systems (pp. 1-20). Cham: Springer.

Kyvik, S. (1990). Age and scientific productivity. Differences between fields of learning. Scientometrics., $19(1), 37-55$.

Kyvik, S., \& Aksnes, D. W. (2015). Explaining the increase in publication productivity among academic staff: A generational perspective. Studies in Higher Education, 40, 1438-1453.

Kyvik, S., \& Larsen, I. M. (1994). International contact and research performance. Scientometrics, 29, 161-172.

Kyvik, S., \& Larsen, I. M. (1997). The exchange of knowledge. A small country in the international research community. Science Communication., 18(3), 238-264.

Kyvik, S., \& Olsen, T. B. (2008). Does the aging of tenured academic staff affect the research performance of universities? Scientometrics, 76(3), 439-455.

Kyvik, S., \& Teigen, M. (1996). Child care, research collaboration, and gender differences in scientific productivity. Science, Technology and Human Values, 21(1), 54-71.

Landry, R., \& Amara, N. (1998). The impact of transaction costs on the institutional structuration of collaborative academic research. Research Policy, 27, 901-913.

Laudel, G. (2002). What do we measure by co-authorships? Research Evaluation, 11(1), 3-15.

Lee, S., \& Bozeman, B. (2005). The impact of research collaboration on scientific productivity. Social Studies in Science, 35(5), 673-702.

Lewis, J. M. (2013). Academic governance. Disciplines and policy. New York: Routledge.

Luukkonen, T., Persson, O., \& Sivertsen, G. (1992). Understanding patterns of international scientific collaboration. Science, Technology, \& Human Values, 17(1), 101-126.

Melin, G. (2000). Pragmatism and self-organization: Research collaboration on the individual level. Research Policy, 29, 31-34.

Merton, R. K. (1973). The sociology of science: Theoretical and empirical investigations. Chicago: University of Chicago Press.

Najduchowska, H., \& Wnuk-Lipińska, E. (1990). Nauczyciele akademiccy 1984 [Academics 1984]. Warsaw and Łódź: IPNISW.

OECD. (2019). Main science and technology indicators. Available from www.oecd.org. Last accessed December 29, 2018. 
Ostrowicka, H., \& Stankiewicz, L. (2018). The truths of business and the lies of academia: The order of discourse on higher education in Poland. Higher Education Research \& Development. On-line first: . https://doi.org/10.1080/07294360.2018.1545746.

Piro, F. N., Aksnes, D. W., \& Rørstad, K. (2013). A macro analysis of productivity differences across fields: Challenges in the measurement of scientific publishing. Journal of the American Society for Information Science and Technology, 64(2), 307-320.

Piro, F. N., Rørstad, K., \& Aksnes, D. W. (2016). How does prolific professors influence on the citation impact of their university departments? Scientometrics, 107(3), 941-961.

Porter, Ch O L H, Itir Gogus, C., \& Yu, R. C.-F. (2010). When does teamwork translate into improved team performance? A resource allocation perspective. Small Group Research., 41(2), 221-248.

Ramsden, P. (1994). Describing and explaining research productivity. Higher Education, 28(2), 207-226.

Rhoades, G., Kiyama, J. M., McCormick, R., \& Quiroz, M. (2008). Local cosmopolitans and cosmopolitan locals: New models of professionals in the academy. The Review of Higher Education., 31(2), 209-235.

Rørstad, K., \& Aksnes, D. W. (2015). Publication rate expressed by age, gender and academic position-A large-scale analysis of Norwegian academic staff. Journal of Informetrics., 9, 317-333.

Rostan, M. (2015). International aspects of academic work and career at the beginning of the twenty-first century. In U. Teichler \& W. K. Cummings (Eds.), Forming, recruiting and managing the academic profession (pp. 241-258). Dordrecht: Springer.

Rostan, M., \& Ceravolo, F. A. (2015). The internationalization of the academy: Convergence and divergence across disciplines. European Review., 23(S1), 38-54.

Rostan, M., Ceravolo, F. A., \& Metcalfe, S. A. (2014). The internationalization of research. In F. Huang, M. Finkelstein, \& M. Rostan (Eds.), The internationalization of the academy. Changes, realities and prospects (pp. 119-144). Dordrecht: Springer.

Santiago, R., Carvalho, T., \& Cardoso, S. (2015). Portuguese Academics' Perceptions of Higher Education Institutions' governance and management: A generational perspective. Studies in Higher Education, $40(8), 1471-1484$.

Scopus (2020). Scopus dataset available from https://www.scopus.com (institutional subscription only).

Shin, J. C., Jung, J., \& Kim, Y. (2014). Teaching and research of Korean academics across career stages. In J. C. Shin, A. Arimoto, W. K. Cummings, \& U. Teichler (Eds.), Teaching and research in contemporary higher education. Systems, activities and rewards (pp. 177-197). Dordrecht: Springer.

Shin, J. C., Kim, Y., Lim, H., Shim, B., \& Choi, Y. (2015). The 'Sandwich Generation' in Korean academe: Between traditional academic authority and meritocratic culture. Studies in Higher Education, 40(8), 1406-1422.

Siemieńska, R. (Ed.). (2019). Kariery akademickie kobiet i mężczyzn. Różne czy podobne?. Warsaw: Scholar.

Smeby, J-Ch., \& Gornitzka, A. (2008). All cosmopolitans now? The changing international contacts of university researchers. In Å. Gornitzka \& L. Langfeldt (Eds.), Borderless knowledge. Understanding "New" internationalisation of research and higher education in Norway (pp. 37-50). Dordrecht: Springer.

Sooryamoorthy, R. (2014). Publication productivity and collaboration of researchers in South Africa: New empirical evidence. Scientometrics, 98, 531-545.

Stephan, P. (2012). How economics shapes science. Cambridge, MA: Harvard University Press.

Stephan, P. E., \& Levin, S. G. (1992). Striking the mother lode in science: The importance of age, place, and time. New York: Oxford University Press.

Teodorescu, D. (2000). Correlates of faculty publication productivity: A cross-national analysis. Higher Education, 39(2), 201-222.

Thelwall, M., \& Maflahi, N. (2019). Academic collaboration rates and citation associations vary substantially between countries and fields. arXiv:1910.00789.

Urbanek, P. (2018). Reform of the higher education system in poland from the perspective of agency theory. European Journal of Higher Education. On-line first, 20 December 2018.

Vabø, A., Padilla-Gonzales, L. E., Waagene, E., \& Naess, T. (2014). Gender and faculty internationalization. In F. Huang, M. Finkelstein, \& M. Rostan (Eds.), The Internationalization of the academy. Changes, realities and prospects (pp. 183-206). Dordrecht: Springer.

Wagner, C. S. (2008). The new invisible college. Science for development. Washington DC: Brookings Institution Press.

Wagner, C. S. (2018). The collaborative era in science. Governing the network. Cham: Palgrave Macmillan.

Wagner, C. S., \& Leydesdorff, L. (2005). Network structure, self-organization, and the growth of international collaboration in science. Research Policy, 34, 1608-1618. 
Wnuk-Lipińska, E. (1996). Innowacyjność a konserwatyzm. Uczelnie polskie w procesie przemian społecznych [Innovation and conservatism. Polish universities and social transformations]. Warsaw: CBPNISW.

Wolszczak-Derlacz, J., \& Parteka, A. (2010). Scientific productivity of public higher education institutions in Poland. A comparative bibliometric analysis. Warsaw: Ernst and Young.

Ziman, J. (1991). Academic science as a system of markets. Higher Education Quarterly, 45(1), 41-61.

Zippel, K. (2017). Women in global science. Stanford: Stanford University Press. 